\title{
Cardiovascular evaluation, including resting and exercise electrocardiography, before participation in competitive sports: cross sectional study
}

\author{
Francesco Sofi, ${ }^{1}$ Andrea Capalbo, ${ }^{1,2}$ Nicola Pucci, ${ }^{1,2}$ Jacopo Giuliattini, ${ }^{2}$ Francesca Condino, ${ }^{2}$ \\ Flavio Alessandri, ${ }^{2}$ Rosanna Abbate, ${ }^{1}$ Gian Franco Gensini, ${ }^{1,2,3,4}$ Sergio Califano ${ }^{2}$
}

\section{EDITORIAL by Drezner and Khan}

${ }^{1}$ Department of Medical and Surgical Critical Area, Thrombosis Centre, University of Florence,

Azienda Ospedaliero-Universitaria Careggi, Florence, Italy

${ }^{2}$ Center for the Study at Molecular and Clinical Level of Chronic, Degenerative and Neoplastic Diseases to Develop Novel Therapies, University of Florence, Italy

${ }^{3}$ Institute of Sports Medicine, Florence, Italy

${ }^{4}$ Don Carlo Gnocchi Foundation, IRCCS, Florence, Italy

Correspondence to: F Sofi, Department of Medical and Surgical Critical Area, Thrombosis Centre, University of Florence, Italy, Viale Morgagni 85, 50134 Florence, Italy francescosofi@gmail.com

Cite this as: $B M J$ 2008;337:a346 doi:10.1136/bmj.a346

\begin{abstract}
Objective To evaluate the clinical usefulness of complete preparticipation cardiovascular screening in a large cohort of sports participants.

Design Cross sectional study of data over a five year period.

Setting Institute of Sports Medicine in Florence, Italy. Participants 30065 (23 570 men) people seeking to obtain clinical eligibility for competitive sports.

Main outcome measures Results of resting and exercise 12 lead electrocardiography.

Results Resting 12 lead ECG patterns showed abnormalities in 1812 (6\%) participants, with the most common abnormalities ( $80 \%$ ) concerning innocent ECG changes. Exercise ECG showed an abnormal pattern in 1459 (4.9\%) participants. Exercise ECG showed cardiac anomalies in 1227 athletes with normal findings on resting ECG. At the end of screening, 196 (0.6\%) participants were considered ineligible for competitive sports. Among the 159 participants who were disqualified at the end of the screening for cardiac reasons, a consistent proportion ( $n=126,79.2 \%)$ had shown innocent or negative findings on resting 12 lead ECG but clear pathological alterations during the exercise test. After adjustment for possible confounders, logistic regression analysis showed that age $>30$ years was significantly associated with an increased risk of being disqualified for cardiac findings during exercise testing. Conclusions Among people seeking to take part in competitive sports, exercise ECG can identify those with cardiac abnormalities. Follow-up studies would show if disqualification of such people would reduce the incidence of CV events among athletes.
\end{abstract}

\section{INTRODUCTION}

Preparticipation screening is the systematic practice of evaluating sports participants before competition to detect cardiovascular abnormalities and thus prevent sudden death or progression of disease. ${ }^{12}$ In Italy, such screening constitutes an established medical programme that has been implemented for more than 25 years. $^{3}$ Over the past few decades, clinicians and experts have debated its clinical usefulness in identifying those at high risk. ${ }^{4-6}$ Corrado et al recently showed a significant decrease in the incidence of sudden death in young Italian athletes who had undergonesuch screening. ${ }^{7}$ The European Society of Cardiology and the International Olympic Committee, taking note of Italy's 25 years of experience, underlined the need for medical examination for young competitive athletes before they take part in organised sports programmes, ${ }^{18}$ though the recently updated recommendations of the American Heart Association do not support this medical perspective. ${ }^{2}$

We analysed data from the Institute of Sports Medicine in Florence, Italy, on cardiovascular evaluation, including resting and exercise electrocardiography, in a large unselected population of sports participants.

\section{METHODS}

\section{Study population}

The study population included 30065 participants who were referred, during a five year period (2002-6), to the Institute of Sports Medicine to obtain eligibility to take part in competitive sports. All participants were examined with first line investigations, as required under Italian law. ${ }^{9}$ Since 1982, people participating in all officially sanctioned sports must undergo medical screening that includes personal and family history, physical examination, and resting and exercise 12 lead electrocardiography (ECG). ${ }^{9}$ Additional tests are requested only for those with positive results in the initial evaluation and are performed by major hospitals or centres other than the institute. Criteria for positive family and personal history, physical examination, and ECGs are those established by Italian protocol and are reported elsewhere. ${ }^{7910}$ All participants gave written informed consent.

\section{Statistical analysis}

Statistical analysis was performed with SPSS (Chicago, IL, USA) software for Windows (version 13.0). Continuous variables were expressed as means and standard deviations (SD) for parametric data or median and range for non-parametric data. We used 
the non-parametric Mann-Whitney test for comparison between single groups, the Kruskal-Wallis test for comparison among different groups, and $\chi^{2}$ to test comparisons between proportions. After adjustment for possible confounders (sex, age group $(<30,30-50$, $>50)$, body mass index (BMI), family history, systolic blood pressure, diastolic blood pressure, smoking habits (yes or no), heart rate, type of sport practised), we carried out logistic regression analysis to evaluate possible predictors of disqualification among athletes with a normal resting ECG pattern. $\mathrm{P}$ value $<0.05$ indicated significance.

\section{RESULTS}

\section{Characteristics of the study population}

The study population included 30065 participants, with significantly $(\mathrm{P}<0.001)$ more men than women $(23570(78.4 \%) v 6495(21.6 \%))$. The mean age was 30.7 (SD 14), with a range of 5-92; 33 were aged over 80 . Nearly $40 \%$ of the total study population were aged over 30 , and $98 \%$ were white. Men were significantly older than women $(28.4 v 24.6 ; \mathrm{P}<0.001)$ and included a significantly higher proportion of smokers $(13.2 \% v$ $10.3 \% ; \mathrm{P}<0.001)$. More than half of the participants were reported to have a sedentary job $(56.2 \%)$, with no significant difference between men and women. Most people spent an average of four to six hours a week doing sports activities (50.9\%), whereas the rest were reported to spend less than four or more than six hours a week $(20.7 \%$ and $28.4 \%$, respectively) taking part in sports.

Participants took part in over 30 different sporting disciplines, the main ones being football and volleyball (31.3\% and $17.7 \%$, respectively). Other leading sports were cycling $(6.7 \%)$, athletics $(5.9 \%)$, and basketball $(5.8 \%)$ among men and swimming $(6.5 \%)$, athletics $(6 \%)$, and gymnastics $(4.2 \%)$ among women.

Personal and family history indicated cardiac abnormalities in less than $0.5 \%$, whereas physical examination reported pathological findings in about $3 \%$.

\section{Resting 12 lead electrocardiography}

Abnormalities on resting ECG were present in 1812 (6\%) participants, $1570(6.7 \%)$ men and $242(3.7 \%)$ women $(\mathrm{P}<0.001)$ (table 1$)$. The most common abnormalities were sinus bradycardia $(2.9 \%)$ and complete $(1.1 \%)$ or incomplete $(0.7 \%)$ right bundle branch blocks, which, together with the type I atrioventricular block and early polarisation pattern,

Table $1 \mid$ Results of 12 lead resting and exercise electrocardiography in people screened before taking part in competitive sports. Figures are number (percentage) of participants

\begin{tabular}{|c|c|c|c|c|}
\hline & All $(n=30065)$ & Men $(n=23570)$ & Women $(n=6495)$ & $P$ value (men $v$ women) \\
\hline \multicolumn{5}{|c|}{ Resting electrocardiography } \\
\hline Normal & $28253(94)$ & $22000(93.3)$ & $6253(96.3)$ & $<0.001$ \\
\hline PVBs & $120(0.4)$ & $95(0.4)$ & $25(0.4)$ & 0.9 \\
\hline PSVBS & $30(0.1)$ & $24(0.1)$ & $6(0.09)$ & 0.9 \\
\hline PEP & $27(0.09)$ & $21(0.09)$ & $6(0.09)$ & 0.7 \\
\hline First degree AVB & $30(0.1)$ & $24(0.1)$ & $6(0.09)$ & 0.9 \\
\hline Second degree AVB & $3(0.01)$ & $3(0.01)$ & - & - \\
\hline LABB & $6(0.02)$ & $5(0.02)$ & $1(0.01)$ & 0.8 \\
\hline RBBB & 331 (1.1) & $306(1.3)$ & $25(0.4)$ & $<0.001$ \\
\hline Sinus bradycardia & $872(2.9)$ & $754(3.2)$ & $118(1.8)$ & $<0.001$ \\
\hline Incomplete RBBB & $210(0.7)$ & $189(0.8)$ & $21(0.3)$ & $<0.001$ \\
\hline ERP & $21(0.07)$ & $19(0.08)$ & $2(0.03)$ & 0.2 \\
\hline ST-T alterations & $150(0.5)$ & $118(0.5)$ & $32(0.5)$ & 0.9 \\
\hline Wandering PM & $3(0.01)$ & $3(0.01)$ & - & - \\
\hline Junctional rhythm & $3(0.01)$ & $3(0.01)$ & - & - \\
\hline $\mathrm{AF}$ & $6(0.02)$ & $6(0.03)$ & - & - \\
\hline \multicolumn{5}{|c|}{ Exercise electrocardiography } \\
\hline Normal & $28606(95.1)$ & $22632(96)$ & $5974(92)$ & $<0.001$ \\
\hline Isolated PVBs & $815(2.7)$ & $524(2.2)$ & $291(4.5)$ & $<0.001$ \\
\hline Isolated PSVBs & $467(1.6)$ & $319(1.4)$ & $148(2.3)$ & $<0.001$ \\
\hline Paired PVBs & $58(0.2)$ & $33(0.1)$ & $25(0.4)$ & $<0.001$ \\
\hline Paired PSVBs & $31(0.1)$ & $14(0.06)$ & $17(0.3)$ & $<0.001$ \\
\hline NSTV & $3(0.01)$ & $2(0.009)$ & $1(0.01)$ & 0.6 \\
\hline SVT & $3(0.01)$ & $2(0.009)$ & $1(0.01)$ & 0.6 \\
\hline ST-T alterations & $54(0.2)$ & $26(0.1)$ & $28(0.4)$ & $<0.001$ \\
\hline Second degree AVB & $8(0.03)$ & $7(0.03)$ & $1(0.01)$ & 0.5 \\
\hline RBBB & $20(0.07)$ & $11(0.05)$ & $9(0.1)$ & 0.01 \\
\hline
\end{tabular}

PVBs=premature ventricular beats; PSVBs=premature supraventricular beats; $P E P=$ pre-excitation pattern; $A V B=a$ trioventricular block; $L A B B=l$ eft anterior bundle block; RBBB=right bundle branch block; $E R P=$ early repolarisation pattern; $P M=$ pacemaker; $A F=$ atrial fibrillation; NSTV=non-sustained ventricular tachycardia; SVT=sustained ventricular tachycardia. 
Table 2 | Causes of disqualification from competitive sports at the end of screening

\begin{tabular}{lcc} 
& No $(\%)$ & Mean age (SD; range) \\
Valve diseases & $47(23.9)$ & $39.9(14.3 ; 18-64)$ \\
\hline Arrhythmias & $36(18.4)$ & $35.4(13.4 ; 12-71)$ \\
\hline Coronary artery disease & $17(8.7)$ & $40.5(13.9 ; 18-83)$ \\
\hline Conduction disorders & $13(6.6)$ & $33.7(19.6 ; 17-69)$ \\
\hline Hypertension & $37(18.9)$ & $42.8(11.3 ; 20-73)$ \\
\hline Cardiomyopathies & $9(4.6)$ & $28.4(13.8 ; 8-63)$ \\
\hline Other* & $37(18.9)$ & $38.9(16.4 ; 15-72)$ \\
\hline
\end{tabular}

*Malignancies, hip and knee prosthesis, venous thromboembolic disease, eye diseases, hearing loss, seizures, mental disorders.

can be considered as innocent modifications that occur in the "athlete's heart." These abnormalities accounted for over $80 \%$ of the total anomalies ( $\mathrm{n}=1464)$. A distinctly abnormal pattern was found in the remaining participants $(348 ; 1.2 \%)$, the most common being ST-T segment alterations and premature ventricular and supraventricular beats. There was a higher prevalence of innocent ECG changes in men than in women, with the exception of type I atrioventricular block.

With regard to age, participants with reported ECG abnormalities were significantly older than those with a normal ECG pattern (31.1 (SD 13.8) v 29.1 (SD 13.1), $\mathrm{P}<0.001)$. Almost half of the population with ECG irregularities comprised participants aged 30-50 $(46.9 \%)$, with the remaining portion mostly being those aged under $30(33.6 \%)$.

\section{Exercise 21 lead electrocardiography}

All participants underwent exercise ECG (table 1), and abnormalities were found in 1459 (4.9\%), with a higher prevalence in women than men $(521(8 \%) v 938(3.9 \%))$. Those with abnormalities were significantly older than those with normal patterns (30.9 (SD 12.1) v 24.9 (SD $9.9), \mathrm{P}<0.001)$, and an equal proportion $(48.9 \%)$ were aged over 30 . The most prevalent anomalies were premature ventricular and supraventricular beats, accounting for over $65 \%$ of the total abnormalities, with a significantly higher prevalence among women than men $(\mathrm{P}<0.001)$. The remaining abnormalities comprised non-sustained and sustained ventricular tachycardia, ST-T segment alterations, and cardiac conduction disorders. Notably, only $232(12.8 \%)$ participants with abnormalities on resting ECG also showed these abnormalities on exercise ECG, but exercise ECG showed cardiac anomalies in 1227 participants (939 men; 288 women; mean age 30.7 (SD 11.9)) in whom resting ECG had shown a normal pattern. In particular, the most prevalent cardiac abnormalities found on stress testing comprised findings suggestive of coronary heart disease and arrhythmias.

\section{Eligibility and screening}

After screening, $196(0.6 \%)$ people were considered ineligible to take part in competitive sports (182 (0.7\%) men and $14(0.2 \%)$ women; mean age 37 (SD 12.3)). In total $159(81.6 \%)$ athletes were disqualified because of cardiac abnormalities, and 37 were disqualified for other reasons (table 2).

By analysing disqualifications according to abnormalities found at resting and exercise ECG, we found that, among the 159 participants disqualified because of cardiac abnormalities, personal history or physical examination, or both, had suggested problems in only $\operatorname{six}(3.7 \%)$ and a large proportion $(126,79.2 \%)$ had a normal pattern on resting ECG. Conversely, almost all the disqualified participants showed some cardiac abnormalities during the exercise ECG. Indeed, in 56 participants with a normal resting ECG, exercise testing showed some potentially fatal cardiac disorders such as arrhythmias and coronary heart disease that resulted in disqualification from competition.

\begin{tabular}{lcc}
\hline Table $3 \mid$ Predictors of disqualification among athletes with normal findings on resting ECG & P value \\
Variable & Odds ratio $(95 \% \mathrm{Cl})$ & 0.4 \\
\hline Sex (men $v$ women) & $0.61(0.20$ to 1.85$)$ & 0.02 \\
\hline Age $30-50$ & $2.38(1.07$ to 5.92$)$ & 0.003 \\
\hline Age $>50$ & $4.49(1.68$ to 11.05$)$ & 0.6 \\
\hline BMl & $1.03(0.93$ to 1.13$)$ & 0.8 \\
\hline Family history & $1.06(0.87$ to 2.34$)$ & 0.7 \\
\hline Diastolic blood pressure $(\mathrm{mm} \mathrm{Hg})$ & $1.01(0.97$ to 1.05$)$ & 0.6 \\
\hline Systolic blood pressure $(\mathrm{mm} \mathrm{Hg})$ & $0.99(0.97$ to 1.02$)$ & 0.3 \\
\hline Type of sport practised & $0.94(0.83$ to 1.06$)$ & 0.3 \\
\hline Heart rate $(\mathrm{bpm})$ & $0.99(0.96$ to 1.01$)$ & 0.2 \\
\hline Smoking habit & $0.59(0.28$ to 1.29$)$ &
\end{tabular}




\section{WHAT IS ALREADY KNOWN ON THIS TOPIC}

Cardiovascular events during sports are tragic occurrences that attract public and media attention

Evaluation of competitive athletes before participation might reduce the risk of cardiovascular death or events during competition

\section{WHAT THIS STUDY ADDS}

The inclusion of resting and exercise electrocardiography to the standard medical evaluation of sports participants helps to identify those at high risk

Exercise electrocardiography can show clear pathological findings in participants with negative or innocent findings at physical examination and resting electrocardiography

Finally, we performed a logistic regression analysis to investigate possible predictors of disqualification among the group of participants with a normal resting ECG. After adjustment for possible confounders we found that the risk of being disqualified increased significantly with age. Participants aged over 30 had a significantly increased risk of showing cardiac abnormalities on exercise ECG, thus resulting in disqualification from competition (table 3 ).

\section{DISCUSSION}

Findings from this cross sectional study, although only preliminary and not supported by follow-up analyses, support the inclusion of resting and exercise ECGs to detect cardiac abnormalities such as ventricular and supraventricular arrhythmias and coronary heart disease among people taking part in competitive sports, especially those who are middle aged and older. A consistent proportion of people disqualified for cardiac disorders showed innocent or negative findings on resting 12 lead ECG but clear pathological alterations on exercise ECG.

Over the past few decades, there has been increasing interest in the role of cardiovascular screening to identify potentially fatal cardiac disorders among athletes before they take part in competitive sports. ${ }^{1-71112}$ Routine use, however, is far from accepted and still raises several important unresolved questions of ethical and practical importance. First of all, the clinical importance of changes in the athlete's heart on ECG is not fully established. In our analysis, as in previous studies, ${ }^{12}$ the most prevalent abnormalities on resting ECG were typical of an athlete's heart. In this scenario, the implementation of ECG screening would probably result in a large number of borderline and false positive results, leading to additional tests to resolve the clinical ambiguity, worry and emotional stress for the participants, and considerable financial costs. On the other hand, some participants with innocent abnormalities showed a clear pathological pattern on exercise ECG, resulting in disqualification from competition. This is in line with results of Pelliccia et al, who recently showed that an abnormal repolarisation pattern, generally regarded as an innocent consequence of athletic conditioning, might represent the initial expression of underlying disease, thus meriting further clinical consideration. ${ }^{13}$

The cost of such a programme is also important. In Italy it costs an estimated $€ 30(£ 24, \$ 47)$ per participant. The implementation of such a programme would definitely result in additional costs for the National Health Service and for the population as a whole. Nevertheless, decreasing the risk of sudden death among competitors is extremely important as it has a considerable impact on both lay and medical communities because of the broadly held view that athletes constitute the healthiest people in society.

\section{Limitations}

Because of the observational design of this study, we were unable to show if these clinical evaluations are effective in reducing the risk of mortality or incidence of cardiac accidents in sports participants. Only a prospective analysis of these data will help us to test this hypothesis. None the less, some previous studies have reported on the clinical efficacy of such cardiovascular screening on reducing sudden death among athletes. ${ }^{7113}$ Moreover, results of second line investigations in participants with a positive screening result are not available, making it difficult to interpret the real diagnostic power of baseline and exercise ECGs, as well as the important matter of false positive results.

Our study, however, provides relevant information especially for middle aged and elderly people participating in sports, and shows a significant prevalence of some potentially fatal cardiac diseases such as coronary heart disease and hypertension.

We thank James Wood for his valuable contribution in the revision of the manuscript.

Contributors: All the authors participated in study design, analysis, interpretation of results, drafting of the article, and approval of the final draft. FS is guarantor

Funding: None

Competing interests: None declared

Ethical approval: Research ethics board of the Institute of Sports Medicine of Florence.

Provenance and peer review: Not commissioned; externally peer reviewed.

1 Corrado D, Pelliccia A, Bjornstad HH, Vanhees L, Biffi A, Borjesson M, et al. Cardiovascular pre-participation screening of young competitive athletes for prevention of sudden death: proposal for a common European protocol. Eur Heart J 2005;26:516-24.

2 Maron BJ, Thompson PD, Ackerman MJ, Balady G, Berger S, Cohen D, et al. Recommendations and considerations related to preparticipation screening for cardiovascular abnormalities in competitive athletes: 2007 update. Circulation 2007;115:1643-55.

3 Di Luigi L, Pelliccia A, Bonetti A, Francavilla G, Ganzit GP, Veicsteinas A, et al. Clinical efficacy and preventive role of the preparticipation physical examination in Italy. Med Sport 2004;57:243-70.

4 Chaitman BR. An electrocardiogram should not be included in routine pre-participation screening of young athletes. Circulation 2007;116:2610-5

5 Myerburg RJ, Vetter VL. Electrocardiograms should be included in preparticipation screening of athletes. Circulation 2007;116:2616-26.

6 Pelliccia A. The preparticipation cardiovascular screening of competitive athletes: is it time to change the customary clinical practice? Eur Heart / 2007;28:2703-5.

7 Corrado D, Basso C, Pavei A, Michieli P, Schiavon M, Thiene G. Trends in sudden cardiovascular death in young competitive athlete after 
implementation of a pre-participation screening program. JAMA 2006;296:1593-601.

8 IOC Medical Commission, International Olympic Committee. Sudden cardiovascular death in sport. Lausanne recommendations: pre participation cardiovascular screening.

2004. http://multimedia.olympic.org/pdf/en report 886.pdf

9 DM 18/2/1982 con norme integrative del DM 28/2/1983 "Norme per la tutela della attività sportive agonistica e non agonistica". http:// www.fmsitv.org.

10 Delise P, Guiducci U, Zeppilli P, D’Andrea L, Proto C, Bettini R, et al. Consensus document by the Italian Society of Sports Cardiology; Italian Association of Out-of-Hospital Cardiologists; Italian Association of Hospital Cardiologists; Italian Federation of Sports Medicine. Cardiological guidelines for competitive sports eligibility. Ital Heart J 2005;6:661-702.
11 Pelliccia A, Di Paolo FM, Corrado D, Buccolieri C, Quattrini FM, Pisicchio $C$, et al. Evidence for efficacy of the Italian national preparticipation screening programme for identification of hypertrophic cardiomyopathy in competitive athlete. Eur Heart J 2006;27:2196-200.

12 Pelliccia A, Culasso F, Di Paolo FM, Accettura D, Cantore R, Castagna W, et al. Prevalence of abnormal electrocardiograms in a large, unselected population undergoing pre-participation cardiovascular screening. Eur Heart J 2007;28:2006-10.

13 Pelliccia A, Di Paolo FM, Quattrini FM, Basso C, Culasso F, Popoli G, et al. Outcomes in athlete with marked ECG repolarization abnormalities. N Engl J Med 2008;358:152-61.

\title{
Association between muscular strength and mortality in men: prospective cohort study
}

\author{
Jonatan R Ruiz, ${ }^{1,2}$ Xuemei Sui, ${ }^{3}$ Felipe Lobelo, ${ }^{3}$ James R Morrow Jr, ${ }^{4}$ Allen W Jackson, ${ }^{4}$ Michael Sjöström, ${ }^{1}$ \\ Steven N Blair ${ }^{3,4}$
}

${ }^{1}$ Department of Biosciences and Nutrition at NOVUM, Unit for Preventive Nutrition, Karolinska Institutet, Huddinge, Sweden

${ }^{2}$ Department of Physiology,

School of Medicine, University of Granada, Spain

${ }^{3}$ Department of Exercise Science, Arnold School of Public Health,

University of South Carolina,

Columbia, SC, USA

${ }^{4}$ Department of Kinesiology,

Health Promotion, and Recreation,

University of North Texas, Denton,

TX, USA

Correspondence to: J R Ruiz

ruizj@ugr.es

Cite this as: $B M J$ 2008;337:a439 doi:10.1136/bmj.a439
This article is an abridged version of a paper that was published on bmj.com. Cite this article as: $B M J$ 2008;337:a439

\section{ABSTRACT}

Objective To examine prospectively the association between muscular strength and mortality from all causes, cardiovascular disease, and cancer in men.

Design Prospective cohort study.

Setting Aerobics centre longitudinal study.

Participants 8762 men aged 20-80.

Main outcome measures All cause mortality up to 31 December 2003; muscular strength, quantified by combining one repetition maximal measures for leg and bench presses and further categorised as age specific thirds of the combined strength variable; and cardiorespiratory fitness assessed by a maximal exercise test on a treadmill.

Results During an average follow-up of 18.9 years, 503 deaths occurred (145 cardiovascular disease, 199 cancer). Age adjusted death rates per 10000 person years across incremental thirds of muscular strength were 38.9, 25.9, and 26.6 for all causes; $12.1,7.6$, and 6.6 for cardiovascular disease; and 6.1, 4.9, and 4.2 for cancer (all P<0.01 for linear trend). After adjusting for age, physical activity, smoking, alcohol intake, body mass index, baseline medical conditions, and family history of cardiovascular disease, hazard ratios across incrementa thirds of muscular strength for all cause mortality were 1.0 (referent), 0.72 (95\% confidence interval 0.58 to 0.90 ), and 0.77 (0.62 to 0.96); for death from cardiovascular disease were 1.0 (referent), 0.74 (0.50 to 1.10), and 0.71 (0.47 to 1.07); and for death from cancer were 1.0 (referent), 0.72 (0.51 to 1.00), and 0.68 (0.48 to 0.97). The pattern of the association between muscular strength and death from all causes and cancer persisted after further adjustment for cardiorespiratory fitness; however, the association between muscular strength and death from cardiovascular disease was attenuated after further adjustment for cardiorespiratory fitness.

Conclusion Muscular strength is inversely and independently associated with death from all causes and cancer in men, even after adjusting for cardiorespiratory fitness and other potential confounders.

\section{INTRODUCTION}

Several studies have shown an inverse association between muscular strength and all cause mortality, ${ }^{1-13}$ but most had limitations. We examined the importance of muscular strength as a predictor of death from all causes, cardiovascular disease, and cancer in a cohort of men. We also examined the association of muscular strength and cardiorespiratory fitness with mortality risk.

\section{METHODS}

Between 1980 and 1989, 10265 men received a medical examination and muscular strength test and were enrolled in the aerobics centre longitudinal study. They were periodically examined. The death rate for the subgroup of men in this analysis is not significantly different from the overall cohort adjusted for age, risk factor, health status, and family history.

Participants performed a maximal graded treadmill test to assess their cardiorespiratory fitness. After exclusions, 8762 predominantly white, well educated, men aged 20-82 from the middle and upper socioeconomic strata were followed up from the date of the baseline examination until the date of death or 31 December 2003. Mortality surveillance was by the National Death Index. ${ }^{14}$

The clinical examination and measures of muscular strength and cardiorespiratory fitness are described elsewhere. ${ }^{15-17}$ Briefly, the baseline examination included a physical examination and measurements of body mass index, systolic and diastolic blood pressure, and concentrations of total and high density lipoprotein cholesterol, triglycerides, and glucose. Participants completed a questionnaire on medical history, including myocardial infarction, stroke, hypertension, diabetes, or cancer; a family history of 
cardiovascular disease or cancer; smoking status; alcohol intake; and physical activity.

We assessed muscular strength in the upper and lower body using a standardised strength testing protocol of variable resistance. Upper body strength was assessed with a one repetition maximum bench press and lower body strength with a one repetition maximum leg press. We computed a score for muscular strength by combining the standardised values of bench and leg presses (see bmj.com). We calculated the score separately for each age group (20-29, 30-39, 40-49, 50-59, and $\geq 60)$. The score for muscular strength was calculated as the mean of the two standardised scores (bench and leg presses). For analysis we used thirds of the age specific composite strength score.

We assessed cardiorespiratory fitness by a maximal treadmill test using a modified Balke protocol. ${ }^{1518}$ Most participants achieved maximal effort. We estimated maximal metabolic equivalents from the final treadmill speed and grade. ${ }^{19} \mathrm{We}$ dichotomised cardiorespiratory fitness as unfit and fit corresponding to the lower $20 \%$ and upper $80 \%$ of the age specific distribution of treadmill exercise duration in the overall population of the aerobics centre longitudinal study. ${ }^{20-24}$ We computed person years of exposure as the sum of follow-up time among decedents and survivors.

\section{Statistical analysis}

We calculated the baseline characteristics of the study population by vital status and thirds of muscular strength. Differences in covariates were tested using Student $t$ tests, $\chi^{2}$ tests, and $\mathrm{F}$ tests. We used Cox proportional hazards regression to estimate hazard ratios, 95\% confidence intervals, and deaths per 10000 person years of follow-up, according to exposure categories. We adjusted multivariable analyses for age (model 1); for age, physical activity, smoking, alcohol intake, body mass index, baseline medical conditions (hypertension, diabetes, or hypercholesterolaemia), and family history of cardiovascular disease (model 2); and after further adjustment for cardiorespiratory fitness (model 3).

To determine differences by age and body mass index, we examined muscular strength and mortality in younger men $(<60)$ and older men $(\geq 60)$ and in men of normal weight $\left(18.5-24.9 \mathrm{~kg} / \mathrm{m}^{2}\right)$ and overweight men $\left(\geq 25 \mathrm{~kg} / \mathrm{m}^{2}\right)$. Finally, we examined the combined effects of muscular strength and cardiorespiratory fitness on all cause mortality by creating six categories for combinations of strength and fitness on the basis of thirds of muscular strength, which we dichotomised in to fit and unfit groups. We compared the effect of each combination group (see bmj.com) with the referent group (low strength, unfit). We calculated two sided $\mathrm{P}$ values and we considered those $<0.05$ as significant.

\section{RESULTS}

During an average follow-up of 18.9 years and 165251 person years of observation $503(5.7 \%)$ deaths occurred: 145 (28.8\%) from cardiovascular disease and 199 (39.6\%) from cancer. Muscular strength, exercise duration, and maximal metabolic equivalents were significantly higher in survivors than in decedents. A direct gradient of treadmill test

\begin{tabular}{|c|c|c|c|c|c|}
\hline \multicolumn{6}{|c|}{ Rates and hazard ratios for mortality in men from all causes, cardiovascular disease, and cancer by thirds of muscular strength } \\
\hline \multirow[b]{2}{*}{ Mortality (third) } & \multirow[b]{2}{*}{ No of deaths } & \multirow{2}{*}{$\begin{array}{l}\text { Age adjusted rate per } \\
10000 \text { person years }\end{array}$} & \multicolumn{3}{|c|}{ Hazard ratio $(95 \% \mathrm{Cl})$} \\
\hline & & & Model 1* & Model $2 \dagger$ & Model 3‡ \\
\hline \multicolumn{6}{|l|}{ All causes: } \\
\hline Lower & 214 & 38.9 & 1.00 (Referent) & 1.00 (Referent) & 1.00 (Referent) \\
\hline Middle & 143 & 25.9 & $0.66(0.54$ to 0.82$)$ & $0.72(0.58$ to 0.90$)$ & $0.74(0.59$ to 0.91$)$ \\
\hline Upper & 146 & 26.6 & $0.68(0.55$ to 0.84$)$ & 0.77 (0.62 to 0.96$)$ & 0.80 (0.64 to 0.996$)$ \\
\hline $\mathrm{P}$ for linear trend & & & $<0.001$ & 0.01 & 0.03 \\
\hline \multicolumn{6}{|c|}{ Cardiovascular disease: } \\
\hline Lower & 66 & 12.1 & 1.00 (Referent) & 1.00 (Referent) & 1.00 (Referent) \\
\hline Middle & 42 & 6.6 & 0.63 (0.43 to 0.93$)$ & $0.74(0.50$ to 1.10$)$ & $0.78(0.52$ to 1.16$)$ \\
\hline Upper & 37 & 7.6 & 0.55 (0.37 to 0.82$)$ & 0.71 (0.47 to 1.07$)$ & $0.78(0.51$ to 1.20$)$ \\
\hline P for linear trend & & & 0.003 & 0.09 & 0.22 \\
\hline \multicolumn{6}{|l|}{ Cancer: } \\
\hline Lower & 88 & 6.1 & 1.00 (Referent) & 1.00 (Referent) & 1.00 (Referent) \\
\hline Middle & 58 & 4.2 & 0.66 (0.47 to 0.92$)$ & 0.72 (0.51 to 1.00$)$ & 0.71 (0.50 to 0.996$)$ \\
\hline Upper & 53 & 4.9 & 0.60 (0.43 to 0.85$)$ & $0.68(0.48$ to 0.97$)$ & 0.67 (0.47 to 0.96$)$ \\
\hline $\mathrm{P}$ for linear trend & & & 0.003 & 0.03 & 0.02 \\
\hline
\end{tabular}

*Adjusted for age.

†Adjusted for age, physical activity, current smoking, alcohol intake, body mass index, baseline medical conditions, and family history of cardiovascular disease.

$\ddagger$ Adjusted for age plus physical activity, current smoking, alcohol intake, body mass index, baseline medical conditions, family history of cardiovascular disease, and cardiorespiratory fitness. 


\section{WHAT IS ALREADY KNOWN ON THIS TOPIC}

Cardiorespiratory fitness provides strong and independent prognostic information about the overall risk of illness and death

Most prospective studies examining the association between muscular strength and death have had limitations

\section{WHAT THIS STUDY ADDS}

Muscular strength in major muscle groups is independently associated with death from all causes and cancer in men aged 20-82

These findings are valid for those who are normal weight or overweight, younger or older, and even after adjusting for a number of potential confounders including cardiorespiratory fitness

Muscular strength seems to add to the protective effect of cardiorespiratory fitness against the risk of death in men

duration across thirds of muscular strength was observed. Age, body mass index, blood pressure, and levels of total cholesterol, triglycerides, and glucose were higher in decedents and in those with lower levels of muscular strength.

All cause mortality was $1.50(38.9 / 25.9)$ and 1.46 $(38.9 / 26.6)$ times greater for those in the lowest third of muscular strength than for those in the middle and upper thirds of muscular strength (table). The differences for death from cardiovascular disease were $1.83(12.1 / 6.6)$ and $1.59(12.1 / 7.6)$ times greater, and for death from cancer were 1.45 (6.1) $4.2)$ and $1.24(6.1 / 4.9)$ times greater. The age adjusted results of model 1 showed a notably declining risk of death from all causes, cardiovascular disease, and cancer across incremental thirds of muscular strength $(\mathrm{P}<0.01$ for linear trend). After the additional adjustments (model 2), risks of death from all causes and cancer remained progressively lower with higher levels of muscular strength $(\mathrm{P}<0.05)$, whereas the association between muscular strength and death from cardiovascular disease was attenuated $(\mathrm{P}=0.08)$. After further adjustment for cardiorespiratory fitness the association between muscular strength and risks of death from all causes or cancer remained significant $(\mathrm{P}<0.05)$, whereas the association between muscular strength and risk of death from cardiovascular disease was no longer statistically significant $(\mathrm{P}=0.23)$.

Strong statistical evidence existed of an interaction between muscular strength and age in predicting death from all causes and cancer (see bmj.com) but weak evidence of an interaction between muscular strength and body mass index in predicting such deaths (see bmj.com). A significant inverse gradient was found for death from all causes and cancer across incremental thirds of muscular strength within each age group $(\mathrm{P}<0.05$ for linear trend $)$. Across age strata, those in the lowest third of muscular strength had a 1.4 -fold to 2.2-fold and 1.5-fold to 4.3-fold higher rates of mortality from all causes and cancer than those in the upper third of muscular strength. Muscular strength also was inversely associated with all cause mortality in men of normal weight and overweight men $(\mathrm{P}<0.05)$ and with cancer mortality in overweight men $(\mathrm{P}=0.03$; see bmj.com). Across incremental thirds of muscular strength, age adjusted total death rates per 10000 person years were $32.9,25.6$, and 20.7 in men of normal weight $(\mathrm{P}=0.009)$ and $42.1,26.2$, and 33.8 in overweight men $(\mathrm{P}=0.046)$.

The death rate in unfit men with the lowest muscular strength was the highest among the six muscular strength and cardiorespiratory fitness categories (see bmj.com). The adjusted death rate per 10000 person years was inversely related to muscular strength within the fit cardiorespiratory fitness group $(\mathrm{P}=0.008)$, and inversely related to cardiorespiratory fitness within the lowest third $(\mathrm{P}=0.003)$ and middle third $(\mathrm{P}=0.03)$ of muscular strength.

\section{DISCUSSION}

Muscular strength was significantly and inversely associated with risk of death from all causes and cancer after controlling for potential confounders, including cardiorespiratory fitness. The inverse association was consistent in strata of age $(<60$, $\geq 60)$ and body mass index $\left(18.5-24.9 \mathrm{~kg} / \mathrm{m}^{2}, \geq 25 \mathrm{~kg} /\right.$ $\mathrm{m}^{2}$ ). Muscular strength was significantly and inversely associated with risk of cardiovascular death after controlling for age, yet the association was attenuated once other potential confounders were entered in the model and was not significant after further adjustment for cardiorespiratory fitness. The age adjusted death rate in men with high levels of both muscular strength and cardiorespiratory fitness was $60 \%$ lower $(\mathrm{P}<0.001)$ than the death rate in unfit men with the lowest levels of muscular strength.

Muscular strength and cardiorespiratory fitness were moderately correlated, suggesting that the association between muscular strength and risk of death from cancer works at least partially through different mechanisms than those associated with the protective effects of cardiorespiratory fitness. In this cohort the number of deaths from cardiovascular disease was lower than that from cancer (145 and 199). This may have reduced the statistical power to detect a significant independent association between muscular strength and risk of death from cardiovascular disease.

Muscle fibre type and configuration has a genetic component and influences strength, yet it is clear that resistance type physical activities are major determinants of muscular strength. ${ }^{25}{ }^{26}$ We have reported a strong and positive association between the frequency of self reported resistance exercise and maximal muscular strength in men. ${ }^{17}$ Results from intervention studies indicate that resistance training enhances muscular strength and endurance, muscle mass, functional capacity, daily physical activity, risk 
profile for cardiovascular disease, and quality of life. ${ }^{25}$ These factors are well known predictors of higher risk of mortality. We observed an inverse association between muscular strength and risk of death from all causes and cancer in older men $(\geq 60)$ and younger men $(<60)$.

We showed an inverse association between muscular strength and risk of death from all causes and cancer in overweight and obese men, as well as between muscular strength and risk of all cause mortality in those of normal body weight.

\section{Strengths and limitations}

Although our findings applied to well educated white men of middle to upper socioeconomic status we have no reason to believe that the benefits of muscular strength would be different in other ethnic or socioeconomic groups. Values for blood pressure and cholesterol levels, body weight, and cardiorespiratory fitness from participants in the aerobics centre longitudinal study were similar to those reported in two population based studies in North America. ${ }^{15}$ No detailed information about drug use or diet was available, which may have biased the results through residual confounding. It seems unlikely, however, that these factors would account for all of the observed association between muscular strength and mortality.

A major strength of this study was the inclusion of objective and standardised maximal tests for muscular strength and cardiorespiratory fitness using reliable measurement protocols in a large cohort of men with extensive follow-up. Moreover, participants were healthy enough to achieve at least $85 \%$ of aged predicted maximal heart rate during the treadmill test.

\section{Conclusions}

Muscular strength seems to add to the protective effect of cardiorespiratory fitness against the risk of death in men. It might be possible to reduce all cause mortality among men by promoting regular resistance training involving the major muscle groups of the upper and lower body two or three days a week. ${ }^{25}$

We thank the doctors and technicians at the Cooper Clinic who collected the baseline data and staff at the Cooper Institute for data entry and data management.

Contributors: See bmj.com.

Funding: The aerobics centre longitudinal study was supported by the National Institutes of Health (grants AG06945, HL62508); the Spanish Ministry of Education (AP2003-2128, EX-2007-1124); the Margit and Folke Pehrzon Foundation; the European Union, in the framework of the public health programme (ALPHA project, 2006120); the American Heart Association predoctoral fellowship; and the American College of Sports Medicine Paffenbarger-Blair fund for epidemiological research on physical activity.

Competing interests: None declared.

Ethical approval: This study was approved by the Cooper Institute

institutional review board.

Provenance and peer review: Not commissioned; externally peer reviewed.
1 Phillips P. Grip strength, mental performance and nutritional status as indicators of mortality risk among female geriatric patients. Age Ageing 1986;15:53-6.

2 Fujita Y, Nakamura Y, Hiraoka J, Kobayashi K, Sakata K, Nagai M, et al. Physical-strength tests and mortality among visitors to healthpromotion centers in Japan. J Clin Epidemiol 1995;48:1349-59.

3 Laukkanen P, Heikkinen E, Kauppinen M. Muscle strength and mobility as predictors of survival in 75-84-year-old people. Age Ageing 1995;24:468-73.

4 Katzmarzyk PT, Craig CL. Musculoskeletal fitness and risk of mortality. Med Sci Sports Exerc 2002;34:740-4.

5 Metter EJ, Talbot LA, Schrager M, Conwit R. Skeletal muscle strength as a predictor of all-cause mortality in healthy men. J Gerontol A Biol Sci Med Sci 2002;57:B359-65.

6 Gale CR, Martyn CN, Cooper C, Sayer AA. Grip strength, body composition, and mortality. Int J Epidemiol 2007;36:228-35.

7 Sasaki H, Kasagi F, Yamada M, Fujita S. Grip strength predicts causespecific mortality in middle-aged and elderly persons. Am J Med 2007;120:337-42.

8 Al Snih S, Markides KS, Ray L, Ostir GV, Goodwin JS. Handgrip strength and mortality in older Mexican Americans. J Am Geriatr Soc 2002;50:1250-6.

9 Rantanen T, Volpato S, Ferrucci L, Heikkinen E, Fried LP, Guralnik JM. Handgrip strength and cause-specific and total mortality in older disabled women: exploring the mechanism. J Am Geriatr Soc 2003;51:636-41.

10 Rantanen T, Harris T, Leveille SG, Visser M, Foley D, Masaki K, et al. Muscle strength and body mass index as long-term predictors of mortality in initially healthy men. J Gerontol A Biol Sci Med Sci 2000;55:M168-73.

11 Newman AB, Kupelian V, Visser M, Simonsick EM, Goodpaster BH, Kritchevsky SB, et al. Strength, but not muscle mass, is associated with mortality in the health, aging and body composition study cohort. J Gerontol A Biol Sci Med Sci 2006;61:72-7.

12 Swallow EB, Reyes D, Hopkinson NS, Man WD, Porcher R, Cetti EJ, etal. Quadriceps strength predicts mortality in patients with moderate to severe chronic obstructive pulmonary disease. Thorax 2007;62:115-20.

13 Rantanen T, Era P, Heikkinen E. Physical activity and the changes in maximal isometric strength in men and women from the age of 75 to 80 years. J Am Geriatr Soc 1997;45:1439-45.

14 Stampfer MJ, Willett WC, Speizer FE, Dysert DC, Lipnick R, Rosner B, et al. Test of the National Death Index. Am J Epidemio 1984;119:837-9.

15 Blair SN, Kohl HW 3rd, Paffenbarger RS Jr, Clark DG, Cooper KH, Gibbons LW. Physical fitness and all-cause mortality. A prospective study of healthy men and women. JAMA 1989;262:2395-401.

16 Jurca R, Lamonte MJ, Barlow CE, Kampert JB, Church TS, Blair SN. Association of muscular strength with incidence of metabolic syndrome in men. Med Sci Sports Exerc 2005;37:1849-55.

17 Jurca R, Lamonte MJ, Church TS, Earnest CP, Fitzgerald SJ, Barlow CE, et al. Associations of muscle strength and fitness with metabolic syndrome in men. Med Sci Sports Exerc 2004;36:1301-7.

18 Balke B, Ware RW. An experimental study of physical fitness of air force personnel. US Armed Forces Med J 1959;10:675-88.

19 American College of Sports Medicine. ACSM's guidelines for exercise testing and prescription, 7th ed. Philadelphia: Lippincott Williams and Wilkins, 2005.

20 Sui X, LaMonte MJ, Blair SN. Cardiorespiratory fitness as a predictor of nonfatal cardiovascular events in asymptomatic women and men. $\mathrm{Am}$ J Epidemiol 2007;165:1413-23.

21 Sui X, LaMonte MJ, Blair SN. Cardiorespiratory fitness and risk of nonfatal cardiovascular disease in women and men with hypertension. Am J Hypertens 2007;20:608-15.

22 Blair SN, Kampert JB, Kohl HW 3rd, Barlow CE, Macera CA, Paffenbarger RS Jr, et al. Influences of cardiorespiratory fitness and other precursors on cardiovascular disease and all-cause mortality in men and women. JAMA 1996;276:205-10.

23 Lee CD, Blair SN, Jackson AS. Cardiorespiratory fitness, body composition, and all-cause and cardiovascular disease mortality in men. Am J Clin Nutr 1999;69:373-80.

24 Wei M, Kampert JB, Barlow CE, Nichaman MZ, Gibbons LW, Paffenbarger RS Jr, et al. Relationship between low cardiorespiratory fitness and mortality in normal-weight, overweight, and obese men. JAMA 1999;282:1547-53.

25 Williams MA, Haskell WL, Ades PA, Amsterdam EA, Bittner V, Franklin BA, et al. Resistance exercise in individuals with and without cardiovascular disease: 2007 update: a scientific statement from the American Heart Association Council on Clinical Cardiology and Council on Nutrition, Physical Activity, and Metabolism. Circulation 2007;116:572-84

26 Thomis MA, Beunen GP, Maes HH, Blimkie CJ, Van Leemputte M, Claessens AL, et al. Strength training: importance of genetic factors. Med Sci Sports Exerc 1998;30:724-31.

Accepted: 16 June 2008 


\title{
Neuromuscular training and the risk of leg injuries in female floorball players: cluster randomised controlled study
}

\author{
Kati Pasanen, ${ }^{1}$ Jari Parkkari, ${ }^{1}$ Matti Pasanen, ${ }^{2}$ Hannele Hiilloskorpi, ${ }^{1}$ Tanja Mäkinen, ${ }^{1}$ Markku Järvinen, ${ }^{4}$ \\ Pekka Kannus ${ }^{3}$
}

${ }^{1}$ Tampere Research Center of Sports Medicine, UKK Institute for Health Promotion Research, FIN-33501 Tampere, Finland

${ }^{2}$ UKK Institute for Health Promotion Research

${ }^{3}$ Injury and Osteoporosis Research Center, UKK Institute for Health Promotion Research

${ }^{4}$ Department of Surgery, Tampere University Hospital and Medical School, University of Tampere Correspondence to: K Pasanen kati.pasanen@uta.fi

Cite this as: BMJ 2008;337:a295 doi:10.1136/bmj.a295
This article is an abridged version of a paper that was published on bmj.com. Cite this article as: $B M J$ 2008;337:a295.

\section{ABSTRACT}

Objective To investigate whether a neuromuscular training programme is effective in preventing non-contact leg injuries in female floorball players.

Design Cluster randomised controlled study. Setting 28 top level female floorball teams in Finland. Participants 457 players (mean age 24 years)-256 (14 teams) in the intervention group and 201 (14 teams) in the control group-followed up for one league season (six months).

Intervention A neuromuscular training programme to enhance players' motor skills and body control, as well as to activate and prepare their neuromuscular system for sports specific manoeuvres.

Main outcome measure Acute non-contact injuries of the legs.

Results During the season, 72 acute non-contact leg injuries occurred, 20 in the intervention group and 52 in the control group. The injury incidence per 1000 hours playing and practise in the intervention group was 0.65 (95\% confidence interval 0.37 to 1.13 ) and in the control group was 2.08 (1.58 to 2.72). The risk of non-contact leg injury was $66 \%$ lower (adjusted incidence rate ratio 0.34 $95 \%$ confidence interval 0.20 to 0.57 ) in the intervention group.

Conclusion A neuromuscular training programme was effective in preventing acute non-contact injuries of the legs in female floorball players. Neuromuscular training can be recommended in the weekly training of these athletes.

Trial registration Current Controlled Trials ISRCTN26550281.

\section{INTRODUCTION}

Studies have shown a reduced risk of ankle and knee injuries among athletes using a neuromuscular training programme,${ }^{1-7}$ whereas some intervention studies have found no such reduction. ${ }^{89}$ The methodological quality of the interventions has, however, been heterogeneous. ${ }^{10}$

Floorball, a hockey type sport played indoors, has become popular in Europe. The sport results in many injuries, with the knee and ankle joints most commonly affected $^{11-14} ; 59 \%$ of acute ankle injuries and $46 \%$ of acute knee injuries occur through non-contact situations. ${ }^{14}$ We investigated whether a neuromuscular training programme could reduce the risk of acute noncontact leg injuries in female floorball players.

\section{METHODS}

Of 477 players from 28 floorball teams that agreed to participate, 457 were eligible for the study. Using the team as the unit of randomisation we carried out stratified cluster randomisation to the intervention and control groups at league level. The statistician (MP) who carried out the computer generated randomisation was not involved in the intervention.

We informed the teams allocated to the intervention group about the training programme. Teams in the control group were asked to continue with usual training.

The neuromuscular training programme took place over six months. At the start of the intervention period we educated one or two team members from each intervention group on use of the programme. Each intervention team was provided with an instruction booklet, equipment (see bmj.com), and exercise diary. During the intervention period the instructors kept a diary of the content and duration of each session and number of participants.

The programme was designed to enhance players' motor skills and body control and to prepare the neuromuscular system for sports specific manoeuvres. The programme consisted of running techniques, balance and body control, plyometrics, and strengthening exercises (see bmj.com). The main point of each exercise was to focus on proper techniques. The aim of the training was to improve control of the back, knees, and ankles during sports specific manoeuvres.

The training sessions, lasting 20-30 minutes, were carried out just before the floorball exercises. During the floorball season training was divided into two intensive training periods (neuromuscular training twice or three times weekly) and two maintenance training periods with one training session (weekly). Intensive training took place at the start of the season and during the break from games in December. Over the competitive season the exercises were followed through with maintenance training.

The primary outcome was an acute leg injury that occurred in non-contact circumstances. A secondary outcome was any injury to the legs. We defined an injury as acute if it occurred during a scheduled game or practice, preventing the player from practising for 24 hours. The severity of injuries was defined as minor (absence from practise for 1-7 days), moderate (absence for 8-28 days), and major (absence for $>28$ days). ${ }^{15}$ 


\section{Data collection}

At baseline, players completed a questionnaire on background information. During follow-up coaches recorded the players' scheduled practice and game hours in a diary and noted injured players. Injuries were recorded by players using a structured questionnaire, including the time, place, cause, type, location, and severity of the injury. After each followup month the coaches mailed the diaries and questionnaires to the study doctor (TM). She contacted players after each new injury and checked the accuracy of the data but was not involved in the intervention.

\section{Statistical analysis}

We expressed the incidence (95\% confidence interval) of injury as the number of injuries per 1000 hours of floorball practise and play. One way analysis of variance was used to estimate the intracluster correlation coefficients of incidence rates for injury. The unadjusted and adjusted incidence rate ratio between the two groups (intervention $v$ control) was obtained from two level Poisson regression models. We considered a $\mathrm{P}$ value $<0.05$ to be significant. In the data analysis by multilevel modelling we took the cluster randomisation into account. Adjustments were done at individual and team levels. We did analyses according to the intention to treat principle. In addition to the intention to treat analyses, we carried out efficacy analyses to evaluate the potential benefits of high compliance (training at least three times a week during the first intensive period, at least twice a week during the second intensive period, and at least once a week during the maintenance periods) and adherence to training.

\section{RESULTS}

See bmj.com for the flow of participants through the study. The consent rate was high $(86 \%$ of players from 28 teams) and the dropout rate low (5\%). Twenty one players dropped out during the study period because of severe injury: nine from the intervention group (eight knee ligament ruptures and one rotator cuff rupture of the shoulder) and 12 from the control group (six knee ligament ruptures, four ankle ligament ruptures, and one lumbar disc prolapse). Data from these players were included in the analyses for the time they participated.

Players in both groups were similar for age, body mass index, experience of floorball, and hours spent in training and play (see bmj.com). No significant differences were found between the groups in number of previous injuries, operations, or preseason training volume. Five teams $(36 \%)$ in the intervention group used the training programme according to schedule, six $(43 \%)$ had some irregularities, and three $(21 \%)$ interrupted training. A mean $74 \%$ of the intended training sessions was carried out as planned.

Participation in the intervention during the first intensive and maintenance periods was more active than during the second periods (see bmj.com).

\section{Injury incidence}

Overall, 32327 scheduled hours of training and play and $87 \mathrm{leg}$ injuries were reported for the intervention group compared with 25019 hours of training and play and 102 leg injuries in the control group.

Significantly fewer non-contact leg injuries (adjusted incident rate ratio $0.34,95 \%$ confidence interval 0.20 to $0.57, \mathrm{P}<0.001$; table) occurred in the intervention group than in the control group. The overall risk of leg injury was significantly different between the groups, favouring the intervention (adjusted incidence rate ratio $0.70,0.52$ to $0.93, \mathrm{P}=0.016)$. This difference was due to a reduction in non-contact leg injuries. The intervention group experienced six ruptures of the anterior cruciate ligament (three non-contact injuries) compared with four in the control group (three noncontact injuries).

In efficacy analysis, intervention teams with high compliance and adherence to the programme had a lower risk of injury than the control group: the incidence rate ratio between the high compliance group and control group for non-contact leg injury was 0.19 (95\% confidence interval 0.06 to $0.64, \mathrm{P}=0.007)$, for non-contact ankle ligament injury was 0.19 (0.05 to $0.82, \mathrm{P}=0.026)$, and for non-contact knee ligament injury was 0.32 (0.04 to $2.59, \mathrm{P}=0.284)$.

\section{DISCUSSION}

A neuromuscular training programme was effective in preventing acute non-contact leg injuries in female

Number and incidence (per 1000 practise and playing hours) of acute non-contact leg injuries and incidence rate ratio for female floorball players receiving neuromuscular training (intervention group) or usual training (control group)

\begin{tabular}{|c|c|c|c|c|c|c|c|c|c|}
\hline \multirow[b]{2}{*}{ Injury type } & \multicolumn{2}{|c|}{$\begin{array}{l}\text { Intervention group } \\
\qquad(n=256)\end{array}$} & \multicolumn{2}{|c|}{ Control group $(n=201)$} & \multirow[b]{2}{*}{ ICC } & \multirow{2}{*}{$\begin{array}{c}\text { Unadjusted } \\
\text { incidence rate ratio } \\
(95 \% \mathrm{Cl})\end{array}$} & \multirow[b]{2}{*}{$P$ value } & \multirow{2}{*}{$\begin{array}{l}\text { Adjusted incidence } \\
\text { rate ratio* }(95 \% \mathrm{Cl})\end{array}$} & \multirow[b]{2}{*}{$P$ value } \\
\hline & No & Incidence $(95 \% \mathrm{Cl})$ & No & Incidence $(95 \% \mathrm{Cl})$ & & & & & \\
\hline Non-contact leg & 20 & $0.65(0.37$ to 1.13$)$ & 52 & 2.08 (1.58 to 2.73$)$ & 0.041 & 0.31 (0.17 to 0.58$)$ & $<0.001$ & $0.34(0.20$ to 0.57$)$ & $<0.001$ \\
\hline Ligament & 15 & $0.48(0.27$ to 0.84$)$ & 38 & 1.52 (1.10 to 2.09$)$ & 0.033 & 0.31 (0.16 to 0.60$)$ & $<0.001$ & 0.35 (0.19 to 0.64$)$ & 0.001 \\
\hline Ankle ligament & 8 & 0.27 (0.11 to 0.64$)$ & 27 & $1.10(0.71$ to 1.70$)$ & 0.059 & 0.24 (0.09 to 0.65$)$ & 0.005 & $0.28(0.12$ to 0.67$)$ & 0.004 \\
\hline Knee ligament & 7 & $0.22(0.10$ to 0.45$)$ & 11 & $0.44(0.24$ to 0.80$)$ & 0.004 & $0.49(0.19$ to 1.27$)$ & 0.143 & $0.49(0.18$ to 1.31$)$ & 0.155 \\
\hline Muscle strain & 5 & 0.15 (0.06 to 0.37$)$ & 14 & 0.57 (0.29 to 1.12$)$ & 0.040 & 0.26 (0.09 to 0.72$)$ & 0.009 & $0.40(0.12$ to 1.32$)$ & 0.134 \\
\hline
\end{tabular}

ICC=intracluster correlation coefficient for incidence of injury. Incidence rate ratio obtained from two level Poisson model. Level of significance was $<0.05$.

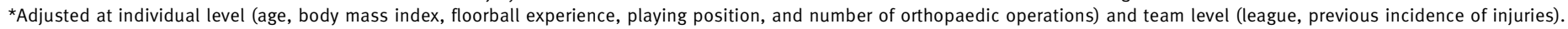

Cluster randomisation was taken into account in data analysis. 


\section{WHAT IS ALREADY KNOWN ON THIS TOPIC}

Floorball players have an increased risk of ligament injuries of the ankle and knee, and about half of these injuries occur in non-contact situations

Studies providing evidence for prevention of sports injuries have been methodologically limited

\section{WHAT THIS STUDY ADDS}

A neuromuscular training programme to enhance the motor skills and body control of female floorball players reduced the risk of leg injury by $66 \%$

The risk of non-contact ankle and knee ligament injury could be reduced by $65 \%$

Neuromuscular training is recommended to be included in the weekly training programme of floorball
Five teams $(36 \%)$ from the intervention group carried out the programme regularly, six $(43 \%)$ had irregularities, and three (21\%) interrupted training. On the basis of information in the exercise diaries and players' subjective estimation of participation, it seemed that training activity was highest during the first two training periods, after which it declined. The intervention teams were included in analyses regardless of training activity and therefore the effect of the programme might be higher than reported. The efficacy analysis confirmed that the risk of injury was lower among teams that trained regularly.

Although severe knee ligament injuries, particularly injuries of the anterior cruciate ligament, are of concern in floorball, we could not analyse the effect of the warmup programme because there were too few such cases. None of these ruptures occurred among the five teams that trained regularly.

Training among controls who already did exercises similar to those of the programme did not reach the level of the intervention group. If this biased the results of the study it erred on the side of underestimating the effect of the training on risk of injury.

This intervention study focused on women floorball players in three top level leagues in Finland. Because floorball players have a similar pattern of leg injuries and injury mechanisms, the training programme could be effective for a range of floorball players.

We thank the players, coaches, and instructors of each participating team, the physiotherapists who participated, and the Finnish Floorball Federation.

Contributors: See bmj.com

Funding: Finnish Ministry of Education and Medical Research Fund of Tampere University Hospital, Tampere, Finland. The funding sources did not have any involvement with the progress of study.

Competing interests: None declared.

Ethical approval: This study was approved by the ethics committee of the Pirkanmaa Hospital District, Tampere, Finland (ETL-code R04072).

Provenance and peer review: Not commissioned; externally peer reviewed. non-contact leg injuries. The $51 \%$ reduction in noncontact knee ligament injuries did not reach significance, but the trend was parallel to that of overall noncontact leg injuries.

\section{Strengths and limitations}

The potential for not achieving double blinding in this type of study limits the strength of the conclusions. The randomisation phase and data collection and analysis were blinded, but the coaches and players could not be blinded. The sample size was sufficient for analyses of non-contact leg injuries but too small for detailed analysis of anatomical subgroups.

The validity of the data was high as $86 \%$ of eligible players participated. In addition, both groups were similar for baseline characteristics, dropout rate, and training and play during follow-up. Compliance in collecting data on exposure and injuries was also good.

The programme was a modified combination of interventions from previous studies, and the exercises were easy to learn. It was designed to reduce the incidence of acute non-contact leg injuries, although contact injuries are common in floorball. ${ }^{14}$
1 Ekstrand J, Gillquist J, Liljedahl S. Prevention of soccer injuries. Supervision by doctor and physiotherapist. Am / Sports Med 1983;11(3):116-20.

2 Hewett TE, Lindenfeld TN, Riccobene JV, Noyes FR. The effect of neuromuscular training on the incidence of knee injury in female athletes. A prospective study. Am J Sports Med 1999;27:699-705. injuries in young female players in European team handball. A prospective intervention study. Scand J Med Sci Sports 1999;9:41-7.

4 Heidt RS, Sweeterman LM, Carlonas RL, Traub JA, Tekulve FX. Avoidance of soccer injuries with preseason conditioning. Am JSports Med 2000;28:659-62

5 Emery CA, Cassidy JD, Klassen TP, Rosychuk RJ, Rowe BH. Effectiveness of a home-based balance-training program in reducing sports-related injuries among healthy adolescents: a cluster randomized controlled trial. CMAJ 2005:172:749-54.

6 Olsen O, Myklebust G, Engebretsen L, Holme I, Bahr R. Exercises to prevent lower limb injuries in youth sports: cluster randomised controlled trial. BMJ 2005;330:1-7.

7 McGuine TA, Keene JS. The effect of a balance training program on the risk of ankle sprains in high school athletes. Am J Sports Med 2006;34:1103-11.

8 Verhagen E, van der BeekA, TwiskJ, Bouter L, Bahr R, van Mechelen W. The effect of a proprioceptive balance training program for the prevention of ankle sprains. A prospective controlled trial. Am/Sports Med 2004;32:1385-93.

9 Söderman K, Werner S, Pietilä T, Engström B, Alfredson H. Balance board training: prevention of traumatic injuries of the lower extremities in female soccer players? A prospective randomized
3 Wedderkopp N, Kaltoft M, Lundgaard B, Froberg K. Prevention of 
intervention study. Knee Surg, Sports Traumatol, Arthrosc 2000;8:356-63.

10 Aaltonen S, Karjalainen H, Heinonen A, ParkkariJ, Kujala U. Prevention of sports injuries. Systematic review of randomized controlled trials. Arch Intern Med 2007;167:1585-92.

11 Snellman K, Parkkari J, Kannus P, LeppäläJ, Vuori I, Järvinen M. Sports injuries in floorball: a prospective one-year follow-up study. Int J Sports Med 2001;22:531-6.

12 Löfgren O, Andersson N, Björnstig U, Lorentzon R. Incidence, nature and causes of floorball injuries. Scand IMed Sci Sports 1994;4:211-4.
13 Wikström J, Andersson C. A prospective study of injuries in licensed floorball players. Scand J Med Sci Sports 1997;7:38-42.

14 Pasanen K, Parkkari J, Kannus P, Rossi L, Palvanen M, Natri A, et al. Injury risk in female floorball. A prospective one-season follow-up. Scand J Med Sci Sports 2008;18:49-54.

15 Ekstrand J, Gillquist J. The avoidability of soccer injuries. Int J Sports Med 1983;4:124-8.

\title{
Secular decline in mortality from coronary heart disease in adults with diabetes mellitus: cohort study
}

\author{
Ane Cecilie Dale, ${ }^{1,4}$ Lars Vatten, ${ }^{2,5}$ Tom Ivar Nilsen, ${ }^{3}$ Kristian Midthjell,, Rune Wiseth ${ }^{1,4}$
}

${ }^{1}$ Department of Circulation and Medical Imaging, Norwegian University of Science and Technology

${ }^{2}$ Department of Public Health, Norwegian University of Science and Technology

${ }^{3}$ Human Movement Science Programme, Norwegian University of Science and Technology

${ }^{4}$ Department of Cardiology, St Olav's University Hospital, NO 7030 Trondheim, Norway

${ }^{5}$ International Agency for Research on Cancer, Lyon, France Correspondence to: A C Dale ane.c.dale@ntnu.no

Cite this as: $B M J$ 2008;337:a236 doi:10.1136/bmi.39582.447998.BE

This article is an abridged version of a paper that was published on bmj.com. Cite this article as $B M J$ 2008;337:a236

\section{ABSTRACT}

Objective To examine trends in fatal coronary heart disease in adults with and without diabetes.

Design Cohort study.

Setting Two surveys of the Nord-Trøndelag health study (HUNT), a population based study in Norway.

Participants 74914 men and women from the first survey (1984-6) and 64829 from the second survey (1995-7).

Main outcome measure. Age specific mortality from coronary heart disease among adults with and without diabetes during two consecutive nine year follow-up periods.

Results A total of 2623 men and 1583 women died from coronary heart disease. Mortality rates were substantially lower during the most recent follow-up period: among men aged 70-79 without diabetes, deaths per 1000 person years declined from 16.38 to 8.79 (reduction 48\%, 95\% confidence interval $39 \%$ to $55 \%$ ) and among women aged $70-79$ from 6.84 to 2.68 (62\%, $52 \%$ to $70 \%$ ). Among the same age group with diabetes, deaths per 1000 person years in men declined from 38.97 to 17.89 (54\%, 32\% to $69 \%$ ) and in women from 28.15 to 11.83 (59\%, 37\% to $73 \%)$. The reduction was more noticeable in age groups younger than 70 at baseline, and less pronounced among people aged 80 or more. Mortality from coronary heart disease was more than twofold higher in people with than without diabetes, with a slightly stronger association in women. The difference in mortality by diabetes status remained almost unchanged from the first to the second survey.

Conclusion The strong general reduction in mortality rates from coronary heart disease from the first to the second follow-up period also benefited people with diabetes, but the more than twofold higher mortality from coronary heart disease associated with diabetes persisted over time.

\section{INTRODUCTION}

Compared with the general population, people with diabetes have a 2-4-fold higher mortality from coronary heart disease. ${ }^{1}$ Studies have also shown a secular decline in such mortality in people with diabetes. ${ }^{2-5}$

We compared mortality rates from coronary heart disease over two consecutive nine year periods in adults who reported diabetes in the 1980s and 1990s. We also studied such mortality among adults without diabetes.

\section{METHODS}

Two population surveys were carried out in NordTrøndelag county, Norway: the first in 1984-6 and the second in 1995-7. Overall, 74977 (88.1\%) adults participated in the first survey and $66140(71.2 \%)$ in the second survey.

Participants in the first survey completed a questionnaire and were measured for blood pressure, pulse, body weight, and height. ${ }^{6}$ We included 74914 people (2100 with diabetes) with data on body weight, height, blood pressure, and diabetes status. Participants in the second survey completed a more comprehensive questionnaire. ${ }^{7}$ We included 64829 people (1951 with diabetes) with data on body weight, height, blood pressure, and diabetes status.

From the baseline questionnaire we collected information on prevalent diabetes and history of cardiovascular disease. We defined those who responded positively to the question "Do you have or have you had diabetes?" to have diabetes.

Body mass index was calculated. We defined hypertension as a blood pressure of 140/90 $\mathrm{mm} \mathrm{Hg}$ or more or as current use of antihypertensives. Exercise reported in the first survey was divided into no regular exercise, once weekly, and twice or more weekly. Exercise reported in the second survey was categorised as no regular exercise, 2-3 hours of light weekly activity, three hours of light activity or one hour of hard activity weekly, and more than one hour of hard activity weekly. Participants self reported smoking status: current, former, or never smokers. We dichotomised education according to duration $(<13$ years or $\geq 13$ years).

We obtained causes of death by linking data from both surveys to the Causes of Death Registry at Statistics Norway. For the follow-up of mortality we calculated person time from the date of participation at baseline (1984-6 for first survey, 1995-7 for second survey) until date of death from coronary heart disease 
or other causes, or until the end of follow-up at 31 December 1993 for the first survey or 31 December 2004 for the second survey.

\section{Statistical analysis}

We calculated age specific mortality rates from coronary heart disease among men and women with and without diabetes during nine consecutive years of follow-up after the first survey and the second survey. A Mantel-Cox comparison was used to calculate mortality rate ratios $(95 \%$ confidence intervals) between the two follow-up periods by sex, age group, and diabetes status.

We also estimated hazard ratios (95\% confidence intervals) of mortality from coronary heart disease between people with and without diabetes. The analysis was done separately for each follow-up period for the whole population and stratified by sex, using Cox regression analysis. Analyses were adjusted for age, body mass index, hypertension status, smoking status, exercise level, and education. We tested for statistical interaction between study period and prevalence of diabetes in relation to mortality from coronary heart disease during follow-up. Departure from the proportional hazards assumption was evaluated using graphical procedures (log-log plots).

\section{RESULTS}

In men the prevalence of diabetes was higher in the second survey than in the first survey, whereas in women the prevalence of diabetes did not increase over time (see bmj.com). Among those with diabetes the mean body mass index was about two units higher in the second survey. Among those without diabetes the mean body mass index was about one unit higher in the second survey. Systolic blood pressure in the second survey was generally lower in all groups, with the greatest reduction in people with diabetes. A lower proportion of men but higher proportion of women reported current smoking in the second survey.

Overall, 15365 people died (see bmj.com). The proportion of deaths from coronary heart disease among people with diabetes at baseline decreased from the first to the second survey (men, $19.7 \%$ to $10.3 \%$; women, $18.2 \%$ to $8.2 \%$ ). Among people without diabetes at baseline, a similar reduction occurred in the proportion of deaths caused by coronary heart disease from the first to the second survey (men, $4.6 \%$ to $2.4 \%$; women, $2.4 \%$ to $1.2 \%$ ).

Among people without diabetes, mortality rates from coronary heart disease were substantially lower during the follow-up period after the second survey (1995-2004) than after the first survey (1984-93), and among men the reduction in mortality rates was more pronounced in younger age groups (table). Thus in people aged 70-79 and without diabetes at baseline the mortality rate from coronary heart disease in men declined from 16.38 to 8.79 deaths per 1000 person years (reduction 48\%, 95\% confidence interval 39\% to $55 \%$ ) and in women declined from 6.84 to 2.68 deaths

\begin{tabular}{|c|c|c|c|c|c|c|c|}
\hline \multicolumn{8}{|c|}{$\begin{array}{l}\text { Mortality rates from coronary heart disease after nine years' follow-up of both first and second surveys of Nord-Trøndelag health } \\
\text { study, and mortality rate ratios from coronary heart disease after second versus first survey }\end{array}$} \\
\hline \multirow[b]{2}{*}{$\begin{array}{l}\text { Age (years) } \\
\text { at baseline }\end{array}$} & \multicolumn{3}{|c|}{ First survey } & \multicolumn{3}{|c|}{ Second survey } & \multirow[b]{2}{*}{$\begin{array}{l}\text { Rate ratios }(95 \% \mathrm{Cl}) \\
\text { second } v \text { first survey }\end{array}$} \\
\hline & $\begin{array}{l}\text { Person } \\
\text { years }\end{array}$ & $\begin{array}{l}\text { No of } \\
\text { deaths }\end{array}$ & Mortality rate* $(95 \% \mathrm{Cl})$ & $\begin{array}{l}\text { Person } \\
\text { years }\end{array}$ & $\begin{array}{l}\text { No of } \\
\text { deaths }\end{array}$ & Mortality rate* $(95 \% \mathrm{Cl})$ & \\
\hline \multicolumn{8}{|l|}{ Men } \\
\hline \multicolumn{8}{|l|}{ No diabetes: } \\
\hline$<60$ & 199282 & 152 & 0.76 (0.65 to 0.89$)$ & 159942 & 41 & 0.26 (0.19 to 0.35$)$ & 0.26 (0.19 to 0.37$)$ \\
\hline $60-69$ & 50175 & 364 & 7.25 (6.55 to 8.04$)$ & 35127 & 83 & 2.36 (1.91 to 2.93$)$ & 0.33 (0.26 to 0.42$)$ \\
\hline $70-79$ & 36620 & 600 & $16.38(15.12$ to 17.75$)$ & 30025 & 264 & 8.79 (7.79 to 9.92$)$ & $0.52(0.45$ to 0.61$)$ \\
\hline$\geq 80$ & 14684 & 520 & 35.41 (32.50 to 38.59) & 13453 & 316 & 23.49 (21.04 to 26.23 ) & 0.67 (0.59 to 0.77$)$ \\
\hline \multicolumn{8}{|l|}{ Diabetes: } \\
\hline$<60$ & 1525 & 7 & 4.59 (2.19 to 9.63$)$ & 1992 & 1 & $0.50(0.07$ to 3.56$)$ & $0.07(0.01$ to 0.84$)$ \\
\hline $60-69$ & 1464 & 45 & $30.73(22.95$ to 41.16$)$ & 1440 & 11 & $7.70(4.26$ to 13.90$)$ & 0.27 (0.14 to 0.52$)$ \\
\hline $70-79$ & 1925 & 75 & 38.97 (31.08 to 48.87$)$ & 2068 & 37 & 17.89 (12.97 to 24.70$)$ & $0.46(0.31$ to 0.68$)$ \\
\hline$\geq 80$ & 1119 & 56 & 50.07 (38.53 to 65.06$)$ & 1096 & 48 & $43.79(33.00$ to 58.10$)$ & 0.92 (0.62 to 1.36$)$ \\
\hline \multicolumn{8}{|l|}{ Women } \\
\hline \multicolumn{8}{|l|}{ No diabetes: } \\
\hline$<60$ & 200991 & 28 & 0.14 (0.10 to 0.20$)$ & 179967 & 4 & 0.02 (0.01 to 0.06$)$ & 0.13 (0.05 to 0.38$)$ \\
\hline $60-69$ & 52072 & 87 & 1.67 (1.35 to 2.06$)$ & 38796 & 35 & 0.90 (0.65 to 1.26$)$ & $0.56(0.38$ to 0.83$)$ \\
\hline $70-79$ & 43588 & 298 & $6.84(6.10$ to 7.66$)$ & 35404 & 95 & 2.68 (2.19 to 3.28$)$ & $0.38(0.30$ to 0.48$)$ \\
\hline$\geq 80$ & 21590 & 468 & 21.68 (19.80 to 23.73$)$ & 21480 & 271 & $12.62(11.20$ to 14.21$)$ & 0.59 (0.50 to 0.68$)$ \\
\hline \multicolumn{8}{|l|}{ Diabetes: } \\
\hline$<60$ & 1160 & 2 & 1.72 (0.43 to 6.89$)$ & 1587 & 1 & 0.63 (0.09 to 4.47$)$ & 0.26 (0.02 to 3.85$)$ \\
\hline $60-69$ & 1645 & 25 & $15.20(10.27$ to 22.50$)$ & 1173 & 2 & $1.71(0.43$ to 6.68$)$ & $0.12(0.03$ to 0.51$)$ \\
\hline $70-79$ & 2842 & 80 & 28.15 (22.61 to 35.04$)$ & 2367 & 28 & $11.83(8.17$ to 17.13$)$ & $0.41(0.27$ to 0.63$)$ \\
\hline$\geq 80$ & 2014 & 104 & 51.63 (42.60 to 62.57$)$ & 2125 & 52 & 24.47 (18.65 to 32.12$)$ & $0.50(0.36$ to 0.71$)$ \\
\hline
\end{tabular}


per 1000 person years (reduction $62 \%, 52 \%$ to $70 \%$ ). In people aged 70-79 and with diabetes at baseline the mortality rate from coronary heart disease in men declined from 38.97 to 17.89 deaths per 1000 person years (reduction $54 \%, 32 \%$ to $69 \%$ ) and in women declined from 28.15 to 11.83 deaths per 1000 person years (reduction 59\%, 37\% to 73\%). The reduction in mortality was stronger in age groups younger than 70 at baseline and less pronounced in those aged 80 or more (table). Mortality rates in women generally resembled those in men about 10 years younger.

The higher mortality associated with diabetes was roughly the same for both follow-up periods (adjusted hazard ratio $2.48,95 \%$ confidence interval 2.19 to 2.81 $v 2.24,1.91$ to 2.64$)$. In sex specific analyses, the association of diabetes with mortality from coronary heart disease was slightly stronger in women than in men for both follow-up periods. Thus the hazard ratios for women with diabetes at baseline compared with those without diabetes at baseline were 2.87 (2.39 to 3.44) after the first survey and 2.71 (2.12 to 3.47) after the second survey. In men the corresponding values were 2.16 (1.81 to 2.57 ) and 1.95 (1.57 to 2.42 ; see bmj.com).

\section{DISCUSSION}

We found a strong and general decline in mortality rates from coronary heart disease irrespective of age, sex, and diabetes status during two consecutive nine years of follow-up after the first and second surveys of the Nord-Trøndelag health study. Throughout the two periods mortality from coronary heart disease in people with diabetes at baseline was more than twofold higher than in those without diabetes at baseline.

As with other studies we found that people who reported diabetes in the most recent cohort (second survey) were on average younger ${ }^{89}$ and the prevalence of diabetes was higher than in the cohort from the first survey. Hypertension was more prevalent in people with diabetes, which might partly explain the increased risk for coronary heart disease associated with diabetes. ${ }^{10-12}$ The prevalence of hypertension decreased from the first survey to the second, but in the second survey still more than half the population with diabetes had hypertension. This suggests that antihypertensive treatment in people with diabetes could have improved during the past decades and that people with diabetes could have benefited both in relation to cardiovascular complications and cardiovascular death.

From the first survey to the second the prevalence of obesity increased in all groups but was more noticeable in men. Obesity was twice as prevalent in people with diabetes and more prevalent in women with diabetes than in men with diabetes. Obesity increases the risk for diabetes, ${ }^{13-17}$ and obesity, alone or with diabetes, moderately increases the risk of mortality from coronary heart disease. ${ }^{18}$ It would therefore be expected that the higher prevalence of obesity in the second survey would yield a slightly higher risk of fatal coronary heart disease than after the first survey. We, however, found the opposite: women with diabetes showed the largest reduction in mortality rates from the first to the second survey. This could have several explanations. A sharp increase in body mass index has occurred in recent years and follow-up in our study may not be sufficiently long to capture the influence of the general weight gain. Also, more effective medical treatment ${ }^{131920}$ after the second survey may have resulted in lower blood pressure and lower prevalence of other risk factors ${ }^{10}$ and could have outweighed the relatively weak ${ }^{18}$ effect of obesity.

The proportion of men who were current smokers decreased between surveys, irrespective of diabetes status, whereas the proportion of women who were current smokers increased. Smoking status therefore cannot explain the decline in fatal coronary heart disease among women with diabetes in this study.

People with diabetes have a higher burden of risk factors for cardiovascular disease than those without diabetes. Despite adjustment for conventional risk factors, ${ }^{21}$ our results showed that people with diabetes still had more than a twofold higher mortality from coronary heart disease.

Other studies have also shown that mortality from coronary heart disease has decreased over the past decades, and it seems that patients with diabetes have also benefited from this reduction. ${ }^{2-5}$ We found a reduction in mortality rates over time for both men and women with diabetes, and our results agree with those of others. ${ }^{3} 4223$

In our study a particularly noticeable reduction in mortality from the first follow-up period to the second follow-up occurred in younger age groups. This could reflect age as a dominant factor but also that elderly people receive less intensive prevention. ${ }^{24}$ It is possible that both incidence and case fatality from cardiovascular disease could have been reduced as a result of better primary prevention and more effective treatment, and that people with prevalent cardiovascular disease now experience longer survival than before.

The awareness of the higher cardiovascular risk associated with diabetes and impaired glucose tolerance has probably intensified cardioprotective treatment in these patients. Lower mortality may be a result

\section{WHAT IS ALREADY KNOWN ON THIS TOPIC}

Mortality rates from coronary heart disease have declined in the Western world during the past 30 years, most rapidly from the mid-1980s

People with diabetes have a 2-4-fold higher mortality from coronary heart disease

\section{WHAT THIS STUDY ADDS}

The strong general decline in mortality coronary heart disease has also benefited people with diabetes

The more than twofold higher risk of dying from coronary heart disease in men and women with diabetes has persisted over time 
of several factors, including a reduced burden of risk factors, ${ }^{1320}$ lower incidence of acute myocardial infarction, ${ }^{25-27}$ improved treatment in the acute phase of coronary events, ${ }^{192628}$ and longer survival resulting from aggressive secondary prevention..$^{25-2729}$ The observation period of the present study coincides with changes in treatment. ${ }^{13202829}$

Our study has some limitations. Diabetes was defined by self reporting but a substudy of the NordTrøndelag health study showed that self reported diabetes was correct in $96.5 \%$ of the cases. ${ }^{30}$ From the start of the first survey to the end of follow-up after the second survey the prevalence of diabetes increased in the general population, although mean random glucose levels in people who reported diabetes were not substantially different in either survey. None the less, a proportion of people without diabetes at baseline probably developed the disease during follow-up. A change in the definition of death from coronary heart disease occurred from the first to the second follow-up periods. This should not affect the mortality ratio between people with and without diabetes during the same follow-up.

We found that during follow-up of mortality over two consecutive nine year periods, the risk of death from coronary heart disease was more than twofold higher in people with diabetes. Mortality rates decreased substantially in all age groups irrespective of sex and diabetes status, suggesting that people with diabetes have also benefited from the overall decline in mortality from coronary heart disease.

Nord-Trøndelag health (HUNT) study is a collaboration between HUNT Research Centre, Faculty of Medicine, Norwegian University of Science and Technology, the Norwegian Institute of Public Health, and Nord-Trøndelag county council.

Contributors: See bmj.com.

Funding: ACT received research fellowship grants from the liaison committee for central Norway regional health authority and the Norwegian University of Science and Technology.

Competing interests: None declared.

Ethical approval: This study was approved by the regional committee for medical research ethics.

Provenance and peer review: Not commissioned; externally peer reviewed.

1 Kannel WB, McGee DL. Diabetes and glucose tolerance as risk factors for cardiovascular disease: the Framingham study. Diabetes Care 1979;2:120-6

2 Lipscombe LL, Hux JE. Trends in diabetes prevalence, incidence, and mortality in Ontario, Canada 1995-2005: a population-based study. Lancet 2007;369:750-6.

3 Fox CS, Coady S, Sorlie PD, Levy D, Meigs JB D’Agostino Sr RB, et al. Trends in cardiovascular complications of diabetes. JAMA 2004;292:2495-9.

4 Thomas RJ, Palumbo PJ, Melton LJ 3rd, Roger VL, Ransom J, O’Brien PC, et al. Trends in the mortality burden associated with diabetes mellitus: a population-based study in Rochester, Minn, 1970-1994. Arch Intern Med 2003;163:445-51.

5 Booth GL, Kapral MK, Fung K, Tu JV. Recent trends in cardiovascular complications among men and women with and without diabetes. Diabetes Care 2006;29:32-7.

6 Holmen J, Midthjell K, Bjartveit K, Hjort PF, Lund-Larsen PG, Moum T, et al. The North-Trøndelag health survey 1984-86. Purpose, background and methods. Participation, non-participation and frequency distribution. Report no 4. Oslo, Norway: Statens Institutt for Folkehelse, Senter for Samfunnsmedisinsk Forskning, 1990.

7 Holmen J, Midthjell K, Krüger $\varnothing$, Langhammer A, Holmen TL, Bratberg GH, et al. The Nord-Trøndelag health study 1995-97
(HUNT 2): objectives, contents, methods and participation. NorJ Epidemiol 2003;13:19-32.

8 Mokdad AH, Ford ES, Bowman BA, Nelson D, Engelgau MM, Vinicor F, et al. Diabetes trends in the US: 1990-1998. Diabetes Care 2000;23:1278-83.

9 Koopman RJ, Mainous AG, Diaz VA, Geesey ME. Changes in age at diagnosis of type 2 diabetes mellitus in the United States, 1988 to 2000. Ann Fam Med 2005;3:60-3.

10 Imperatore G, Cadwell BL, Geiss L, Saadinne JB, Williams DE, Ford ES, et al. Thirty-year trends in cardiovascular risk factor levels among US adults with diabetes: national health and nutrition examination surveys, 1971-2000. Am J Epidemiol 2004;160:531-9.

11 UK Prospective Diabetes Study Group. Tight blood pressure control and risk of macrovascular and microvascular complications in type 2 diabetes: UKPDS 38. BMJ 1998;317:703-13.

12 Saydah SH, Fradkin J, Cowie CC. Poor control of risk factors for vascular disease among adults with previously diagnosed diabetes. JAMA 2004;291:335-42.

13 Ford ES, Ajani UA, Croft JB, Critchley JA, Labarthe DR, Kottke TE, et al. Explaining the decrease in U.S. deaths from coronary disease, 1980 2000. N Engl J Med 2007;356:2388-98.

14 Gregg EW, Cadwell BL, Cheng YJ, Cowie CC, Williams DE, Geiss L et al. Trends in the prevalence and ratio of diagnosed to undiagnosed diabetes according to obesity levels in the US. Diabetes Care 2004;27:2806-12.

15 Mokdad AH, Ford ES, Bowman BA, Dietz WH, Vinicor F, Bales VS, et al. Prevalence of obesity, diabetes, and obesity-related health risk factors, 2001. JAMA 2003;289:76-9.

16 Fox CS, Pencina MJ, Meigs JB, Vasan RS, Levitzky YS, D’Agostino RB. Trends in the incidence of type 2 diabetes mellitus from the 1970 s to the 1990s: the Framingham heart study. Circulation 2006;113:2914-8.

17 Midthjell K, Krüger $\varnothing$, Holmen J, Tverdal A, Claudi T, Bjorndal A, et al. Rapid changes in the prevalence of obesity and known diabetes in an adult Norwegian population. The Nord-Trøndelag health surveys: 1984-1986 and 1995-1997. Diabetes Care 1999;22:1813-20.

18 Bogers RP, Bemelmans WJ, Hoogenveen RT, Boshuizen HC, Woodward M, Knekt P, et al. Association of overweight with increased risk of coronary heart disease partly independent of blood pressure and cholesterol levels: a meta-analysis of 21 cohort studies including more than 300000 persons. Arch Intern Med 2007;167:1720-8.

19 Saaddine JB, Cadwell B, Gregg EW, Engelgau MM, Vinicor F, Imperatore $\mathrm{G}$, et al. Improvements in diabetes processes of care and intermediate outcomes: United States, 1988-2002. Ann Intern Med 2006;144:465-74.

20 Unal B, Critchley JA, Capewell S. Explaining the decline in heart disease mortality in England and Wales between 1981 and 2000 Circulation 2004:109:1101-7.

21 McGuire DK, Rao SV, Joski P, Barsness GW, Peterson ED, Jollis JG, et al. Diabetes is associated with a higher risk of death than is prior myocardial infarction in the setting of coronary disease: results from the Duke Cardiovascular Database. J Am Coll Cardiol 2002,39:329A. (Abstract.)

22 Gu K, Cowie CC, Harris MI. Diabetes and decline in heart disease mortality in US adults. JAMA 1999;281:1291-7.

23 Gregg EW, Gu Q, Cheng YJ, Narayan KM, Cowie CC. Mortality trends in men and women with diabetes, 1971 to 2000 . Ann Intern Med 2007;147:149-55.

24 Tran CT, Laupacis A, Mamdani MM, Tu JV. Effect of age on the use of evidence-based therapies for acute myocardial infarction. Am HeartJ 2004;148:834-41.

25 Ergin A, Muntner P, Sherwin R, He J. Secular trends in cardiovascula disease mortality, incidence, and case fatality rates in adults in the United States. Am J Med 2004;117:219-27.

26 McGovern PG, Jacobs DR, Shahar E, Arnett DK, Folsom AR, Blackburn $\mathrm{H}$, et al. Trends in acute coronary heart disease mortality, morbidity, and medical care from 1985 through 1997: the Minnesota heart survey. Circulation 2001;104:19-24.

27 Arciero TJ, Jacobsen SJ, Reeder GS, Frye RL, Weston SA, Killian JM, et al. Temporal trends in the incidence of coronary disease. Am J Med 2004;117:228-33.

28 Huxley R, Barzi F, Woodward M. Excess risk of fatal coronary heart disease associated with diabetes in men and women: meta-analysis of 37 prospective cohort studies. BMJ 2006;332:73-8.

29 Hunink MG, Goldman L, Tosteson AN, Mittleman MA, Goldman PA, Williams LW, et al. The recent decline in mortality from coronary heart disease, 1980-1990. The effect of secular trends in risk factors and treatment. JAMA 1997;277:535-42.

30 Midthjell K, Holmen J, Bjørndal A, Lund-Larsen G. Is questionnaire information valid in the study of a chronic disease such as diabetes? The Nord-Trøndelag diabetes study. J Epidemiol Community Health 1992;46:537-42.

Accepted: 24 April 2008 


\title{
Imported malaria and high risk groups: observational study using UK surveillance data 1987-2006
}

\author{
Adrian D Smith, ${ }^{1}$ David J Bradley, ${ }^{1,2}$ Valerie Smith, ${ }^{1}$ Marie Blaze, ${ }^{1}$ Ron H Behrens, ${ }^{2}$ Peter L Chiodini, ${ }^{1,2}$ \\ Christopher J M Whitty ${ }^{1,2}$
}

\section{EDITORIAL by Zuckerman}

${ }^{1}$ HPA Malaria Reference

Laboratory, London School of

Hygiene and Tropical Medicine,

London WC1E 6AU

${ }^{2}$ Department of Infectious and

Tropical Diseases, London School

of Hygiene and Tropical Medicine

Correspondence to: A Smith,

Division of Public Health and

Primary Care, University of Oxford,

Oxford OX3 7LF

adrian.smith@dphpc.ox.ac.uk

Cite this as: $B M J$ 2008;337:a120 doi:10.1136/bmj.a120
This article is an abridged version of a paper that was published on bmj.com. Cite this article as BMJ 2008;337:a120

\section{ABSTRACT}

Objective To examine temporal, geographic, and sociodemographic trends in case reporting and case fatality of malaria in the United Kingdom.

Setting National malaria reference laboratory surveillance data in the UK.

Design Observational study using prospectively gathered surveillance data and data on destinations from the international passenger survey.

Participants 39300 cases of proved malaria in the UK between 1987 and 2006.

Main outcome measures Plasmodium species; sociodemographic details (including age, sex, and country of birth and residence); mortality; destination, duration, and purpose of international travel; and use of chemoprophylaxis.

Results Reported cases of imported malaria increased significantly over the 20 years of the study; an increasing proportion was attributable to Plasmodium falciparum ( $P$ falciparum/ $P$ vivax reporting ratio 1.3:1 in 1987-91 and 5.4:1 in 2002-6). $P$ vivax reports declined from 3954 in 1987-91 to 1244 in 2002-6. Case fatality of reported $P$ falciparum malaria did not change over this period (7.4 deaths per 1000 reported cases). Travellers visiting friends and relatives, usually in a country in Africa or Asia from which members of their family migrated, accounted for 13 215/20 488 (64.5\%) of all malaria reported, and reports were geographically concentrated in areas where migrants from Africa and South Asia to the UK have settled. People travelling for this purpose were at significantly higher risk of malaria than other travellers and were less likely to report the use of any chemoprophylaxis (odds ratio of reported chemoprophylaxis use $0.23,95 \%$ confidence interval 0.21 to 0.25 ).

Conclusions Despite the availability of highly effective preventive measures, the preventable burden from falciparum malaria has steadily increased in the UK while vivax malaria has decreased. Provision of targeted and appropriately delivered preventive messages and services for travellers from migrant families visiting friends and relatives should be a priority.

\section{INTRODUCTION}

Malaria acquired in endemic regions and imported into non-endemic countries accounts for a considerable and largely preventable burden of morbidity and mortality every year. We examined malaria notified in the UK in 1987 to 2006 inclusive, with the aim of identifying trends and at risk groups to assist people advising travellers (mainly general practitioners) and those seeing unwell returned travellers (hospital doctors and general practitioners). We hypothesised that the group of travellers descended from migrant families visiting friends and relatives might be particularly at risk.

\section{METHODS}

The Malaria Reference Laboratory, part of the Health Protection Agency, maintains the national surveillance database of reported cases of malaria in the UK. Malaria surveillance is a passive detection system that identifies cases from statutory notification (through local authorities) and from clinicians who send standardised malaria reports for laboratory verification. The notifying laboratory and clinician are requested to provide further information-personal details, details of travel, prophylaxis taken, and details of illness. Methods of case detection, reporting, and transcribing and the information requested from care providers used for this analysis remained unchanged between 1987 and 2006.

We included all reported episodes of malaria in the UK from 1 January 1987 to 31 December 2006 to provide 20 consecutive years. Supplementary information came from records of death certification for all malaria associated deaths and from records of postmortem findings where available. Data on annual passenger numbers from the UK to individual "malarious countries" (as defined by the World Health Organization), by purpose of travel, to selected countries in Africa and South Asia came from the international passenger survey for the years 1987 to 2006 (a questionnaire based survey of a $0.2 \%$ stratified sample of travellers using British ports).

We used bivariate analysis of categorical variables and equality of populations for comparison of nonnormally distributed continuous variables. We used linear regression for analysis of linear trend. For bivariate analyses for which data were incomplete, we compared missing values with collected values.

\section{RESULTS}

Between 1987 and 2006, 39300 cases of malaria were reported to the Malaria Reference Laboratory. Data were largely complete for central variables (age 96\%, sex $94 \%$, date of diagnosis $98 \%$, outcome $99 \%$ ) but less complete for some supplementary information (country of visit $88 \%$, purpose of travel $71 \%$, country of birth $64 \%$, prophylaxis use $62 \%$ ). The median age of cases 


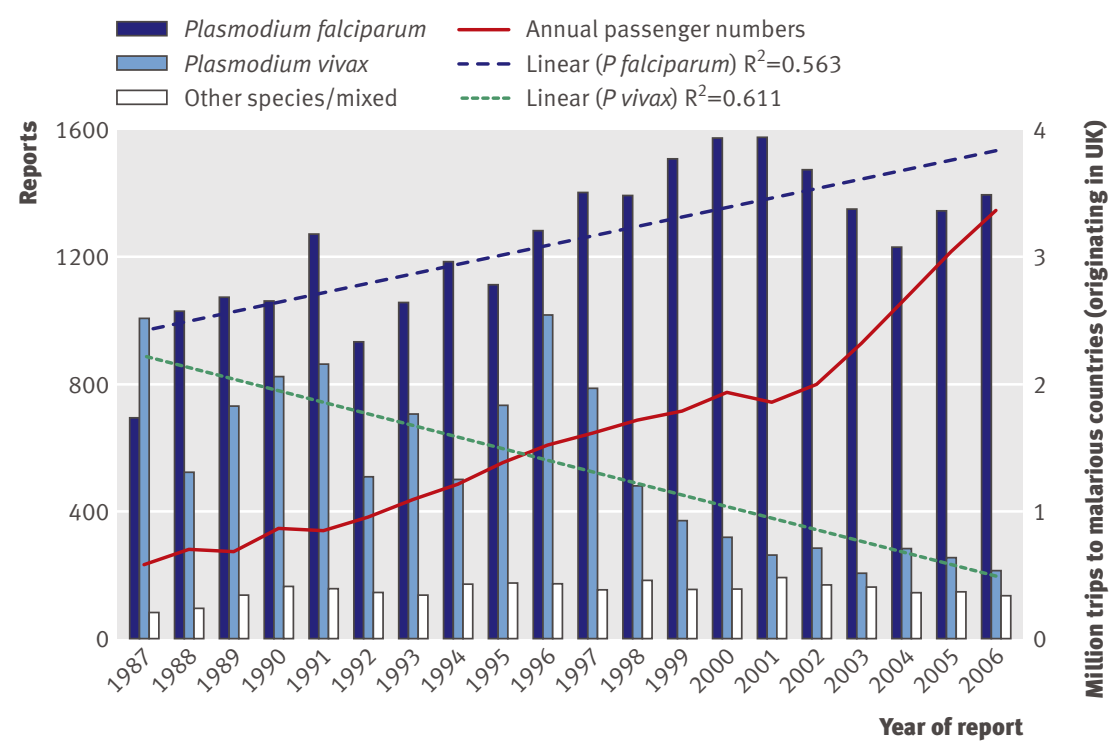

Reported cases of malaria, 1987 to 2006 visits to malarious areas of cases decreased (1987-91, 42 days; 2002-6, 28 days). Of the UK travellers whose reason for travel was known, 13215 (64.5\%, 95\% confidence interval $64 \%$ to $65 \%$ ) had travelled to visit friends or relatives in their own or their families' country of origin. Most, but not all, of these people were visiting countries where their family had some degree of origin. This compares with 4029 cases in people travelling on holiday. The risk of malaria per episode of travel from the UK decreased between 1987 and 2006 for all species of malaria, most notably for $P$ vivax.

Of the 34359 cases with reported travel history, $24599(71.6 \%, 71 \%$ to $72 \%)$ occurred after travel to Africa; this included 20774 of 21541 (96.4\%, 96\% to 97\%) cases of falciparum malaria (see bmj.com). Travel to Nigeria and Ghana accounted for $54 \%$ of all imported P falciparum. People who made trips to visit family in Africa were significantly more likely to have acquired malaria than those travelling for other reasons (risk ratio of reports per 10000 trips $=3.65,95 \%$ confidence interval 3.5 to $3.8 ; \mathrm{P}<0.0001)$.

Travel to South Asia accounted for 8452 cases, $24.6 \%$ (24\% to $25 \%$ ) of imported malaria, of which $92 \%$ was Pvivax. From 1987 to 1991, 3036 cases arose from the Indian subcontinent, accounting for $31 \%$ of all UK malaria. By 2002-6, this had decreased to 705 cases $(8 \%$ of all UK malaria). Of cases in which the purpose of travel was reported, $89 \%$ of UK travellers visiting South Asia had done so to visit family and friends. People travelling for this reason were at significantly higher risk of acquiring malaria than other travellers (risk ratio of reported cases per 10000 trips $=7.9,7.2$ to $\left.8.6 ; \chi^{2} \mathrm{P}<0.0001\right)$.

Of UK travellers with complete records (17 129), only $42 \%$ reported taking any form of chemoprophylaxis against malaria during their period of travel. People who had visited family in their country of origin were less likely to report the use of any prophylaxis than other travellers (Mantel-Haenszel odds ratio adjusted for age and sex $=0.23,95 \%$ confidence interval 0.20 to 0.25 ). Among reported cases in people who travelled to sub-Saharan Africa between 1999 and 2006, over which period consistent recommendations

\begin{tabular}{|c|c|c|c|c|c|c|c|c|c|c|c|c|c|}
\hline \multirow[b]{2}{*}{ Period } & \multicolumn{7}{|c|}{ Reported malaria cases } & \multicolumn{4}{|c|}{$\begin{array}{l}\text { Reported case rate, per } \\
\text { million UK population }\end{array}$} & \multicolumn{2}{|c|}{$\begin{array}{l}\text { Deaths due to } \\
\text { P falciparum }\end{array}$} \\
\hline & $\mathrm{Pf}$ & $\mathrm{Pv}$ & Po & $\mathrm{Pm}$ & $\begin{array}{c}\text { Mix- } \\
\text { ed }\end{array}$ & $\begin{array}{c}\text { Species } \\
\text { not } \\
\text { con- } \\
\text { firmed }\end{array}$ & Total & $\mathrm{Pf}$ & $\mathrm{Pv}$ & Po & $\mathrm{Pm}$ & No & $\begin{array}{c}\text { Case } \\
\text { fatality } \\
\text { (per } 1000 \\
\text { cases) }\end{array}$ \\
\hline 1987-91 & 5120 & 3954 & 513 & 106 & 186 & 12 & 9891 & 17.9 & 13.9 & 1.8 & 0.4 & 35 & 6.8 \\
\hline $1992-6$ & 5546 & 3475 & 638 & 152 & 169 & 1 & 9981 & 19.2 & 12.0 & 2.2 & 0.5 & 41 & 7.4 \\
\hline $1997-2001$ & 7440 & 2231 & 675 & 160 & 80 & 6 & 10592 & 25.4 & 7.6 & 2.3 & 0.6 & 59 & 7.9 \\
\hline $2002-6$ & 6753 & 1244 & 610 & 153 & 69 & 6 & $8836^{*}$ & 22.5 & 4.2 & 2.0 & 0.5 & 48 & 7.1 \\
\hline Total & 24859 & 10904 & 2436 & 571 & 504 & 25 & 39300 & 21.3 & 9.3 & 2.1 & 0.5 & 183 & 7.4 \\
\hline
\end{tabular}

$\mathrm{Pf}=$ Plasmodium falciparum; $\mathrm{Pm}=$ Plasmodium malariae; $\mathrm{Po}=$ Plasmodium ovale; $\mathrm{Pv}=$ Plasmodium vivax.

*Includes one case of $P$ knowlesi. 
Table 2 | Reported cases of malaria 1987-2006, by global region visited (where reported*). Values are numbers (percentages)

\begin{tabular}{|c|c|c|c|c|c|}
\hline Region & Plasmodium falciparum & Plasmodium vivax & Plasmodium ovale & Plasmodium malariae & Total $†$ \\
\hline Africa & $20774(96.4)$ & $950(9.7)$ & $2058(98.0)$ & $480(98.0)$ & 24599 \\
\hline South Asiał & $517(2.4)$ & $7813(80.1)$ & $23(1.1)$ & $3(0.6)$ & 8452 \\
\hline Far East and South East Asia & $114(0.5)$ & $387(4.0)$ & $7(0.3)$ & $2(0.4)$ & 524 \\
\hline Central and South America & $35(0.2)$ & $304(3.1)$ & $3(0.1)$ & $3(0.6)$ & 350 \\
\hline Oceania & $46(0.2)$ & $263(2.7)$ & $7(0.3)$ & $1(0.2)$ & 333 \\
\hline Middle East & $51(0.2)$ & $39(0.4)$ & $3(0.1)$ & $1(0.2)$ & 97 \\
\hline Caribbean & $4(0.01)$ & 0 & 0 & 0 & 4 \\
\hline Total & 21541 & 9756 & 2101 & 490 & 34359 \\
\hline
\end{tabular}

*Excludes 4927 reports with no travel information reported and 14 reports with no known history of travel.

†Includes one $P$ knowlesi, 455 mixed species, and 15 unconfirmed species reports.

$\ddagger$ Afghanistan, Burma (Myanmar), Bhutan, India, Pakistan, Bangladesh, Nepal, and Sri Lanka.

on prophylactic drugs for this region were made, only $7 \%$ of people visiting friends or relatives in their own or their families' country of origin reported having used recommended drugs, compared with $24 \%$ of people travelling for other reasons $\left(\chi^{2} \mathrm{P}<0.0001\right)$.

Forty one per cent of all cases of malaria in the UK, and $65 \%$ of cases of $P$ falciparum malaria, occurred in London residents or visitors to London, whereas most $(68 \%)$ cases of $P$ vivax were reported from other regions of the UK, notably the West Midlands.

Mortality data show that 183 deaths related to falciparum malaria occurred over the period of the study, giving an overall case fatality rate of 7.4 deaths per 1000 cases. Case fatality was significantly lower among people travelling from the UK to visit friends or relatives in their own or their families' country of origin than among people travelling for other reasons $(0.25 \%$ $\left.v 1.9 \% ; \chi^{2}=83.1, \mathrm{P}<0.001\right)$.

\section{DISCUSSION}

This study of more than 39000 cases of malaria imported into the UK shows striking trends. The great majority of malaria is acquired in Africa. $P$ falciparum

\section{WHAT IS ALREADY KNOWN ON THIS TOPIC \\ Falciparum malaria is the most common potentially fatal tropical parasitic infection imported into the UK \\ Increased travel to areas endemic for malaria means that increasing numbers of UK residents are at risk \\ Effective prophylactic and anti-mosquito measures are available}

\section{WHAT THIS STUDY ADDS}

Imported falciparum malaria has been increasing over the past 20 years, but vivax malaria has been decreasing markedly

Most malaria is in travellers visiting friends and relatives in their families' country of origin, especially in west Africa

Uptake of chemoprophylaxis is low in people who acquire malaria, especially travellers from migrant families, and tailoring health messages to migrant groups is a priority malaria has increased steadily; reported cases are not distributed evenly across the population but are concentrated in communities with frequent travel to see friends and relatives, especially in west Africa. Travellers to Nigeria and Ghana account for half of all imported falciparum cases. A minority of travellers with malaria report having used any prophylaxis, and much of that used is inadequate. Vivax malaria imported into the UK has dropped dramatically. Vivax malaria is also a disease of people visiting friends and relatives; most cases are in people who reside outside London.

Targeting messages tailored to groups visiting friends and relatives, especially in west Africa, is essential in primary care and public health. People visiting friends or relatives in their own or their families' country of origin may well expect to visit settings with a higher risk of transmission of malaria than other travellers and to do so for longer periods $\mathrm{s}^{1-3}$; that many do this without the benefit of effective antimalarial chemoprophylaxis, as these and other data suggest, ${ }^{4-7}$ is of concern.

Annual prevalence reports for malaria over the period of our study have documented modest declines in South Asia, smaller than that seen among UK travellers to the region. ${ }^{8}$ One explanation might be that travellers visiting family in the region increasingly stay in urban settings where local control measures have been most effective in reducing local transmission of malaria. The risk-benefit assessment of the routine advice on chemoprophylaxis for South Asia may need to be re-examined, as has been the case for Latin America. $^{9}$

The advantages of large scale, prospectively collected data from surveillance centres collected in an unchanged, standardised way over long periods are clear, but limitations also exist. Under-reporting is inevitable, and laboratories and clinicians differ in the comprehensiveness of their reporting. Previous studies of data from the Malaria Reference Laboratory suggest that they are more complete than most other routinely collected data on malaria and in excess of $50 \%$ complete. ${ }^{10}$ As the methods did not change over this period, under-reporting is unlikely to affect trends 
reported here. Reporting clinicians often did not report information about travel history and prophylaxis, but we found no evidence to suggest that cases with missing information were systematically different from those with complete reports.

This study highlights the need to focus tailored messages on preventing malaria on members and descendants of migrant families visiting friends and relatives, especially in African migrant families. The UK has constantly updated guidelines to assist people advising travellers. ${ }^{11}$

We thank all the laboratories and clinicians who provide data to the Malaria Reference Laboratory.

Contributors: See bmj.com.

Funding: CJMW is supported by the Gates Malaria Partnership, and DJB is a Leverhulme emeritus fellow. All other support is from the Health Protection Agency.

Competing interests: None declared.

Ethical approval: Not needed.

Provenance and peer review: Not commissioned; externally peer reviewed.

1 SchlagenhaufP, Steffen R, Loutan L. Migrants as a major risk group for imported malaria in European countries. J Travel Med 2003;10:106-7.

2 Angell SY, Behrens RH. Risk assessment and disease prevention in travelers visiting friends and relatives. Infect Dis Clin North Am 2005;19:49-65.
3 Bouchaud O, Cot M, Kony S, Durand R, Schiemann R, Ralaimazava P, et al. Do African immigrants living in France have long-term malarial immunity? Am J Trop Med Hyg 2005;72:21-5.

4 Research Group on Imported Infectious Diseases. TropNetEurop sentinel surveillance report: falciparum malaria in 2004. University of Munich, 2005 (available at www.tropnet.net/reports friends/ pdf_reports_friends/mar05_falcmal2004_friends.pdf).

5 Jelinek T, Schulte C, Behrens R, Grobusch MP, Coulaud JP, Bisoffi Z, et al. Imported falciparum malaria in Europe: sentinel surveillance data from the European network on surveillance of imported infectious diseases. Clin Infect Dis 2002;34:572-6.

6 Robinson P, Jenney AW, Tachado M, Yung A, Manitta J, Taylor K, et al. Imported malaria treated in Melbourne, Australia: epidemiology and clinical features in 246 patients. J Travel Med 2001;8:76-81.

7 Casalino E, Le Bras J, Chaussin F, Fichelle A, Bouvet E. Predictive factors of malaria in travelers to areas where malaria is endemic. Arch Intern Med 2002;162:1625-30.

8 Behrens RH, Bisoffi Z, Bjorkman A, Gascon J, Hatz C. Malaria prophylaxis policy for travellers from Europe to the Indian Sub Continent. Malar J 2006;5:653-7.

9 Behrens R, Carroll B, Beran J, Bouchaud O, Hellgren U, Hatz C, et al. The low and declining risk of malaria in travellers to Latin America: is there still an indication for chemoprophylaxis? Malar J 2007;6:114.

10 Davidson RN, Scott JA, Behrens RH, Warhurst D. Under-reporting of malaria, a notifiable disease, in Britain. J Infect 1993;26:348-9.

11 Chiodini P, Hill D, Lalloo D, Lea G, Walker E, Whitty CJM, et al. Guidelines for malaria prevention in travellers from the United Kingdom. London: Health Protection Agency,

2007 (available at www.hpa.org.uk/web/HPAwebFile/HPAweb_C/ 1203496943523)

Accepted: 2 May 2008

\section{Ageing joints}

I love mountains: I love their majesty, their beauty, their massiveness, their remoteness, their everlastingness. And I love what they do to me; they make me feel small in comparison, yet they make me feel big and strong and capable when I reach their summits, they put me at peace with the world and with myself, and at the end of a hard day's walking they leave me with a quite magical mix of physical exhaustion and spiritual fulfilment.

But now my ageing knees are telling me that those big mountain days are soon to be no more. I do the right exercises and I buy the right gear, but I know before too long I shall have to seek advice. This will be in the vain and selfish hope that a miracle can be wrought for me where none exists for others with similar problems.

And I have many mountain friends with similar problems. Their various experiences, when seeking medical advice, have been disappointing. This is not just because no miracle exists for their ageing joints. It is also because so many of their medical advisors - whether GPs, consultants, or physiotherapists - fail to appreciate what the loss of mountain walking will mean. Comments vary from the jocular "I can't understand anyone who wants to slog up a hill all day" and "How can anyone find that fun?" to the worst of all, "Well, what do you expect at your age?"

I wonder if these same professionals greet someone who enjoys painting but whose sight is deteriorating with a similar lack of understanding. And do they tell a lover of music who is hard of hearing that this is all he can expect at his age? I think not. There is something different about medical attitudes to the loss of the ability to exert oneself if that loss is due simply to ageing joints. I suspect the runner, the cyclist, and the tennis player all fall victim to the same sort of comments as the mountain walker, whereas the painter and music lover, with problems also due to ageing may receive understanding and sympathy. We encourage our patients to exercise beyond the needs of everyday living but when their ability to do so decreases we offer little support. We forget that the loss of this ability may mean the loss of their greatest pleasures. Perhaps it is because we find it easier to understand some pleasures than others, so we accept that the ability to paint or to appreciate music must bring great joy, but how can exhaustion from walking 10-15 miles with a couple of mountains en route make anyone happy?

No doubt I shall steel myself to seek advice in due course. And when no miracle exists I shall, nevertheless, be hugely grateful if there is at least an understanding of my loss. Meanwhile, I shall struggle on in the mountains, hoping each time that I climb my beloved Great Gable that it will not be for the last time before my family one day fulfils my wish to have my ashes scattered there.

Ruth Booker retired general practitioner, Twickenham rmgarrod@waitrose.com

Cite this as: $B M J$ 2008;337:a61

We welcome articles up to 600 words on topics such as A memorable patient, A paper that changed my practice, My most unfortunate mistake, or any other piece conveying instruction, pathos or humour. Please submit the article on http://submit.bmj.com Permission is needed from the patient or a relative if an identifiable patient is referred to. We also welcome contributions for "Endpieces" consisting of quotations of up to 80 words (but most are considerably shorter) from any source, ancient or modern, which have appealed to the reader. 